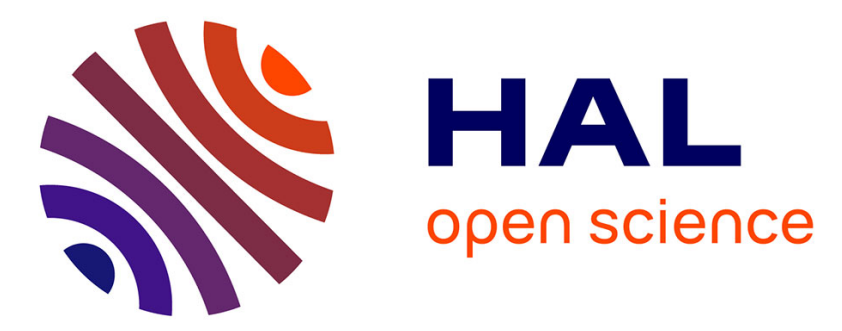

\title{
An Atmospheric Soliton Observed with Doppler Radar, Differential Absorption Lidar, and a Molecular Doppler Lidar
}

Steven E. Koch, Cyrille Flamant, James W. Wilson, Bruce M. Gentry, Brian D. Jamison

\section{To cite this version:}

Steven E. Koch, Cyrille Flamant, James W. Wilson, Bruce M. Gentry, Brian D. Jamison. An Atmospheric Soliton Observed with Doppler Radar, Differential Absorption Lidar, and a Molecular Doppler Lidar. Journal of Atmospheric and Oceanic Technology, 2008, 25 (8), pp.1267-1287. 10.1175/2007JTECHA951.1 . hal-00333901

\section{HAL Id: hal-00333901 https://hal.science/hal-00333901}

Submitted on 28 Apr 2019

HAL is a multi-disciplinary open access archive for the deposit and dissemination of scientific research documents, whether they are published or not. The documents may come from teaching and research institutions in France or abroad, or from public or private research centers.
L'archive ouverte pluridisciplinaire HAL, est destinée au dépôt et à la diffusion de documents scientifiques de niveau recherche, publiés ou non, émanant des établissements d'enseignement et de recherche français ou étrangers, des laboratoires publics ou privés. 


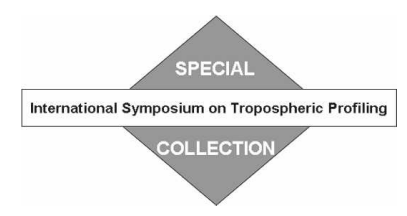

\title{
An Atmospheric Soliton Observed with Doppler Radar, Differential Absorption Lidar, and a Molecular Doppler Lidar
}

\author{
Steven E. Koch \\ NOAA/Earth Systems Research Laboratory, Global Systems Division, Boulder, Colorado \\ Cyrille Flamant \\ Service d'Aéronomie-Institut Pierre-Simon Laplace, CNRS-UPMC-UVSQ, Paris, France \\ JAMES W. WILSON \\ National Center for Atmospheric Research,* Boulder, Colorado \\ BRUCE M. GENTRY \\ NASA Goddard Space Flight Center, Greenbelt, Maryland \\ BRIAN D. JAMISON ${ }^{+}$ \\ NOAA/Earth Systems Research Laboratory, Global Systems Division, Boulder, Colorado
}

(Manuscript received 14 December 2006, in final form 17 August 2007)

\begin{abstract}
Airborne Leandre II differential absorption lidar (DIAL), S-band dual-polarization Doppler radar (SPol), and Goddard Lidar Observatory for Winds (GLOW) Doppler lidar data are used, in conjunction with surface mesonet and special sounding data, to derive the structure and dynamics of a bore and associated solitary wave train (soliton) that were generated in southwestern Kansas during the International $\mathrm{H}_{2} 0$ Project (IHOP_2002). Vertical cross sections of S-Pol reflectivity, S-Pol radial velocity, and DIAL water vapor mixing ratio show a stunning amplitude-ordered train of trapped solitary waves. DIAL data reveal that the leading wave in the soliton increasingly flattened with time as the soliton dissipated.

A method is developed for using the GLOW Doppler winds to obtain the complex two-dimensional vertical circulation accompanying the dissipating soliton. The results show multiple circulations identical in number to the oscillations seen in the S-Pol and DIAL data. The leading updraft occurred precisely at the time that the bore passed over the GLOW facility, as well as when the photon count values suddenly ramped up (suggesting lifting of the low-level inversion by the bore). Additional evidence in support of the validity of the results is provided by the fact that layer displacements computed using the derived vertical motions agree well with those implied by the changes in height of the DIAL mixing ratio surfaces.

The depth and speed of propagation of the bore seen in the DIAL and surface mesoanalyses were shown to be consistent with the predictions from bore hydraulic theory. Analysis of National Center for Atmospheric Research (NCAR) Integrated Sounding System (ISS) data shows that a highly pronounced curvature in the profile of bore-relative winds, related to the existence of a very strong low-level jet, effectively trapped the upward leakage of solitary wave energy below $3 \mathrm{~km}$. This finding explains the trapped lee wave-type structures seen in the DIAL, GLOW, and S-Pol data.
\end{abstract}

* The National Center for Atmospheric Research is sponsored by the National Science Foundation.

\footnotetext{
+ In collaboration with the Cooperative Institute for Research in the Atmosphere (CIRA), Colorado State University, Ft. Collins, Colorado.
}

Corresponding author address: Steven E. Koch, NOAA/ESRL, R/GSD, 325 Broadway, Boulder, CO 80305-3328.

E-mail: steven.koch@noaa.gov 


\section{Introduction}

A key objective of the International $\mathrm{H}_{2} 0$ Project (IHOP_2002), which occurred from 13 May to 25 June 2002 in the southern Great Plains of the United States, was to improve the ability to predict convective rainfall (Weckwerth et al. 2004). The attainment of this goal requires improved understanding of where, when, and why storms develop and the ability to predict the evolution of convective cell and system structure, coverage, and intensity. In general, convergence lines in the boundary layer act as strong focusing agents for triggering new convection or, at times, enhancing existing storms. For this reason, low-level convergence boundaries and associated fields of moisture were a focus in IHOP_2002. Of particular interest in the current study are the convergence zones associated with density currents, bores, and solitons (Doviak and Ge 1984; Droegemeier and Wilhelmson 1985; Wilson and Schreiber 1986; Mueller and Carbone 1987; Karyampudi et al. 1995; Koch and Clark 1999; Knupp 2006).

Density currents are primarily horizontal mass flows driven by their greater density relative to their environments. Thunderstorm outflow boundaries, cold fronts, and sea breezes may all act at times as density currents. An atmospheric internal bore is a gravity-wave phenomenon that propagates on a low-level inversion surface and is typically generated when a density current (such as cold air from a thunderstorm) intrudes into a statically stable layer (Maxworthy 1980; Simpson 1987; Crook 1988; Haase and Smith 1989a,b; Rottman and Simpson 1989). A bore may at times evolve into a family of solitary waves known as a soliton (Christie 1989). A solitary wave consists of a single wave of elevation that propagates without change of form because of a balance between nonlinearity and dispersion. The soliton is characterized by "amplitude-ordering," meaning that the leading solitary wave in the family has the largest amplitude, with each subsequent wave displaying lesser amplitudes.

Density currents, bores, and solitons were observed repeatedly by a multitude of ground-based and airborne remote sensing systems during the 6-week field phase of IHOP_2002. One purpose of this paper is to determine the extent to which the structure of bores and solitons is consistent between observations made by airborne differential absorption lidar (DIAL), ground-based Doppler radar, and Doppler lidar. A second objective is to extend previous applications of Doppler lidar to the study of the detailed vertical structure of mesoscale wave phenomena at scales barely resolvable with this remote sensing system.

The subject of this study is a bore that was generated during the early evening hours on 20 June 2002 and its evolution into a stunning amplitude-ordered train of solitary waves. Section 2 briefly presents some background information about bores, solitons, and density currents. Section 3 describes the instruments used in this study. Radar, surface mesonet, and DIAL observations are discussed in section 4. Doppler lidar analysis techniques are developed in section 5 to obtain the two-dimensional vertical circulation associated with the soliton, which is then related to the structure portrayed in the DIAL and Doppler radar data. The derived structure and dynamics of the bore/soliton are compared with two-layer hydraulic theory and a waveducting analysis using sounding data in section 6 .

\section{Background on density currents, bores, and solitons}

Low-level stratification favors the progressive evolution of density currents into turbulent bores, undular bores, solitons, and, ultimately, solitary waves (Christie et al. 1979; Simpson 1987). A bore is a type of gravity wave that is spawned ahead of a density current as the current intrudes into a stably stratified layer of sufficient depth near the surface. Bore passage typically results in a sustained elevation of the inversion layer. Sometimes a train of amplitude-ordered solitary waves (a soliton) may evolve from bores, but ultimately just the waves may exist without a permanent increase in the depth of the stable layer (Christie 1989). The presence of the density current is no longer critical to the evolution of the bore and solitary waves once they are generated. As the density current begins to intrude into the stably stratified fluid, the fluid first envelops the head of the density current. This fluid then moves away from the density current head as an incipient bore, carrying a remnant of the dense air originally contained in the density current within a closed circulation at the leading edge of the bore in the form of a solitary wave. Laboratory experiments have shown that a family of solitary waves develops because of nonlinear effects and propagates ahead of the density current as the current slows down, but only when a stable waveguide is present at low levels.

The remote sensing systems analyzed in this study will be used, among other things, to estimate the speed of propagation, depth, and amplitude of the bore and solitary waves. According to linear wave theory, the speed of a solitary wave is proportional to the wave amplitude; thus, a dispersive family of waves evolves from the initial bore with amplitudes inversely related to their widths. The hydraulic theory of Rottman and Simpson (1989) predicts that bore propagation speed 
depends on its depth $\left(d_{b}\right)$, the stably stratified boundary layer (SBL) depth $\left(h_{0}\right)$, and the speed of a long gravity wave $\left(C_{\mathrm{gw}}\right)$ according to the formula

$$
C_{\text {bore }} / C_{\mathrm{gw}}=\left[0.5\left(d_{b} / h_{0}\right)\left(1+d_{b} / h_{0}\right)\right]^{1 / 2} .
$$

Koch and Clark (1999) have applied other predictive equations for bore speed to account for such factors as finite fluid depth, an extremely shallow stable layer, and energy loss restricted to the neutral layer above the SBL waveguide (Klemp et al. 1997). In general, the SBL must be sufficiently deep and intense to support a bore of a given strength. The modeling work of Haase and Smith (1989b) and Jin et al. (1996) sheds light on this issue.

"Bore intensity" or amplitude is defined as the ratio of the mean bore depth to the SBL depth $\left(d_{b} / h_{0}\right)$. Smooth (undular) bores are observed in the laboratory for $1<d_{b} / h_{0}<2$; strong, turbulent bores occur when $2<d_{b} / h_{0}<4$; and for even larger values, the bore appears more like a density current because a very shallow inversion has little influence. According to Rottman and Simpson (1989), bore strength increases as a function of two variables, the Froude number ( Fr) and the ratio of the density current (dc) depth to the inversion depth $(H)$, as shown here:

$$
\mathrm{Fr}=\frac{C_{\mathrm{dc}}}{C_{\mathrm{gw}}}=\frac{C_{\mathrm{dc}}}{\left(g \delta \theta h_{0} / \theta_{\mathrm{vw}}\right)^{1 / 2}}=\frac{C_{\mathrm{dc}}}{N h_{0}}
$$

and

$$
H=\frac{d_{\mathrm{dc}}}{h_{0}} .
$$

The potential temperature jump across the inversion is denoted by $\delta \theta$. This theory provides an approach for verifying the bore properties observed by the DIAL and Doppler systems.

It can be difficult to distinguish bores from density currents and solitons. The passage of either a density current or a bore is typically identifiable by an abrupt pressure jump hydrostatically related to the mean cooling throughout the depth of the current. Other identifiers often include a sharp wind shift caused by the horizontal gradient of the pressure perturbation field and increased gustiness due to strong vertical mixing. The degree of cooling should be hydrostatically consistent with the sustained surface pressure increase that follows an initial abrupt pressure jump, as recorded in sensitive surface microbarograph data. Cooling associated with density currents is primarily caused by horizontal advection of the denser air, whereas adiabatic ascent causes cooling in the case of a bore. Thus, pronounced surface cooling is not characteristic of bores.
In fact, weak warming (and drying) may occur as the result of turbulent downward mixing of warmer (and typically drier) air from above the inversion into the SBL.

Density currents also may generate gravity waves other than bores and solitary waves. Model simulations show that trapped lee-type waves may be forced by a strong flow over the head of the density current (Jin et al. 1996). Trapped lee waves display no vertical tilt and are motionless relative to the density current head. Lee-wave trapping occurs only under a very special condition in which the Scorer parameter decreases sufficiently rapidly with height. In addition, KelvinHelmholtz waves may be produced within a thin region of strong vertical wind shear between the body of cold air in the density current and the air above it (Droegemeier and Wilhelmson 1985; Mueller and Carbone 1987). Such waves propagate rearward relative to the density current head, in contrast to trapped lee waves.

\section{Instrument description}

Of particular importance to the current study was the availability of DIAL and Doppler lidar to study the detailed structure of these lower-tropospheric phenomena. Lidar offers the ability to achieve high-vertical resolution profiles in clear air with essentially no degradation due to ground clutter. It is, however, unable to penetrate clouds and precipitation and has more limited range than weather radars and wind profiling systems. The DIAL method provides detailed profiles of the water vapor mixing ratio by comparing the returned signals, which are tuned precisely to a water vapor line, with those from a nearby spectral region lacking water vapor absorption (Bösenberg 1998). For the 20 June 2002 bore event, the Leandre II DIAL system was flown aboard the Naval Research Laboratory (NRL) P-3 aircraft in a downward-pointing direction from a nearly constant altitude of $4.5 \mathrm{~km} \mathrm{AGL}$, essentially perpendicular to the bore and wave fronts. This allowed for direct visualization of the solitary waves and other features in their plane of propagation. Mixing ratio measurements made by the Leandre II DIAL system have a precision greater than $0.5 \mathrm{~g} \mathrm{~kg}^{-1}$ and an accuracy greater than $1 \%\left(\sim 0.05 \mathrm{~g} \mathrm{~kg}^{-1}\right)$ in the altitude range of $0-5 \mathrm{~km}$. Measurements were made with vertical and horizontal resolutions of 300 and $800 \mathrm{~m}$, respectively (Bruneau et al. 2001a,b).

The Goddard Lidar Observatory for Winds (GLOW) lidar (Gentry et al. 2000) was located at the Homestead profiling site in the Oklahoma Panhandle (labeled "HISS" in Fig. 1), along with a large number of other instruments. GLOW is a mobile direct-detection Dopp- 


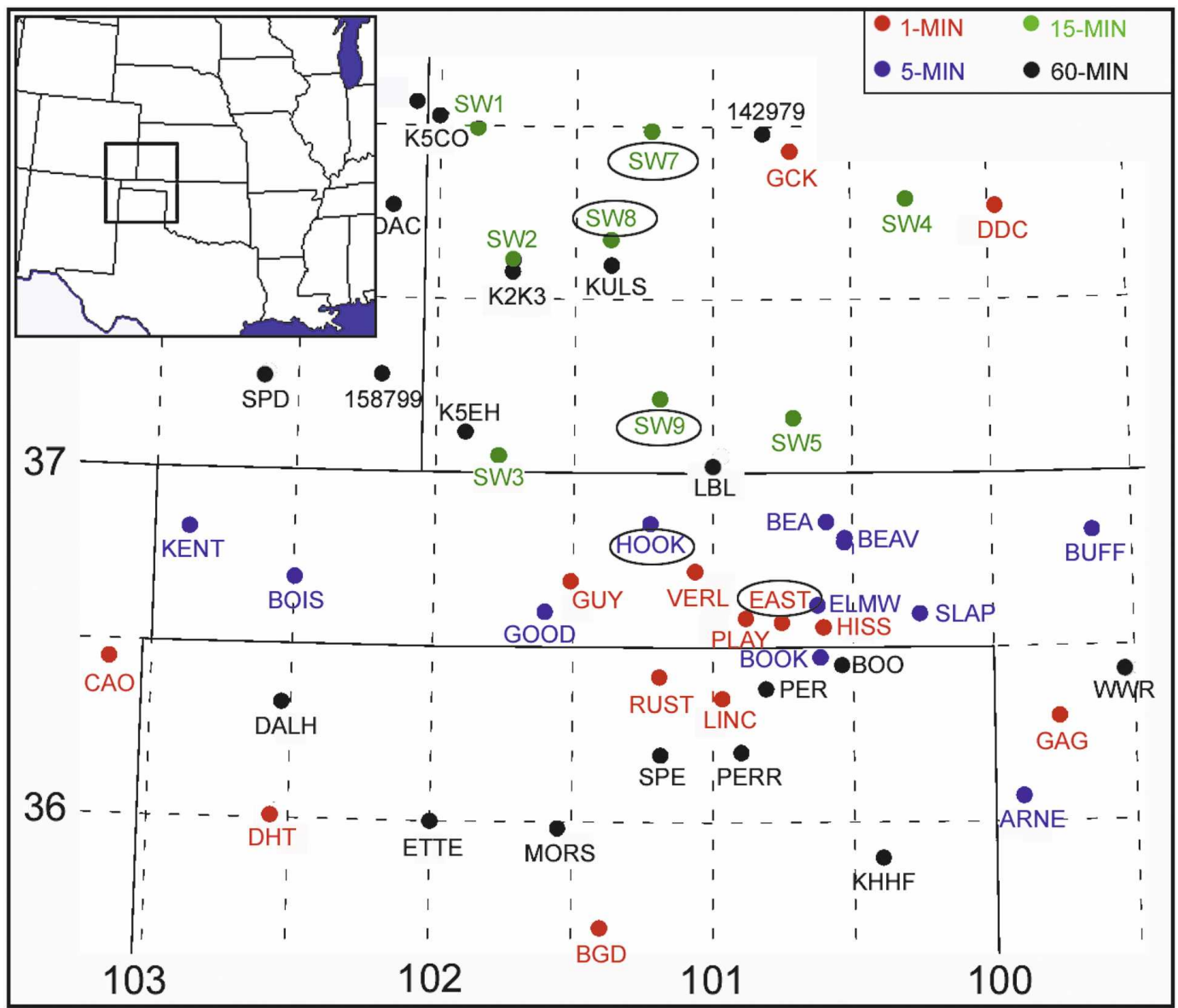

FIG. 1. Surface mesonetwork stations providing data in the region of the Oklahoma Panhandle for this study during IHOP_2002. Time series are shown in Figs. 7 and 8 for the circled stations, which are on a line directed parallel to the movement of the density current-bore-soliton system. Red and blue stations provided dry bulb temperature, dewpoint temperature, mean sea level pressure, precipitation, and wind speed and direction data at 1- and 5-min sampling resolutions, respectively. The southwest Kansas mesonet (green stations) provided dry bulb temperature, relative humidity, precipitation, wind speed and direction, wind gust, and radiation values at 15-min intervals (but, notably, no pressure data). Black stations provided dry bulb temperature, dewpoint temperature, mean sea level pressure, precipitation, wind speed and direction, and wind gust data at a 60-min sampling resolution. Most of the remote sensing systems, including GLOW, were located at the Homestead facility (labeled "HISS"). The S-Pol was located at EAST, which is $15 \mathrm{~km}$ west of Homestead.

ler lidar system that uses the double-edge technique to measure the Doppler shift of the molecular and aerosol backscattered lidar energy to obtain wind profiles in the clear air up to the stratosphere. Direct-detection Doppler lidar is an optical analog of Doppler radar in the sense that the frequency shift of the returned signal is caused by the motion of the scattering target away from or toward the transmitter. In the case of the lidar, the scattering particles are the air molecules or aerosols rather than the millimeter- or larger-scale scatterers observed by the radar. The double-edge method utilizes two high-spectral resolution etalon optical filters located symmetrically about the outgoing laser frequency to measure the Doppler frequency shift. Radial winds are calculated from changes in the ratio of the detected signals in the filter channels (Gentry and Chen 2002), and the horizontal wind components are then determined from the four slant profiles. A third etalon channel is used to make a zero-Doppler reference measurement of the outgoing laser frequency. There is a small $1 \%-2 \%$ dependence of the instrument spectral response on temperature due to spectral broadening by the random thermal motion of the molecules.

Raw measurements are available with a resolution of $45 \mathrm{~m}$ in range and $3.5 \mathrm{~min}$ in time. The temporal resolution is determined by the fact that first GLOW "stares" for $30 \mathrm{~s}$ at a fixed $30^{\circ}$ elevation angle along each of the four cardinal directions (north, east, south, 
and finally west), and then a vertically pointing scan is performed, which is used only for calibration purposes instead of as a correction term in the calculation of the Cartesian coordinates (this is discussed in greater length in section 5a). GLOW was operated during IHOP_2002 with low average laser power (0.05-0.4 W versus normal $0.7 \mathrm{~W}$ ) to keep the response of the photon-counting detectors as linear as reasonably possible in the lowest few kilometers of the atmosphere. This required spatial averaging to obtain good performance above the boundary layer. The wind speed and direction profiles reported in this study were processed with a vertical resolution of $150 \mathrm{~m}$ but no temporal averaging. This effective sample resolution represented a trade-off between needing the highest possible resolution and keeping the noise level acceptably low.

The National Center for Atmospheric Research (NCAR) S-band (2.8-GHz transmitter frequency) dualpolarization Doppler radar (S-Pol; Lutz et al. 1995), with $0.91^{\circ}$ beamwidth, was located $15 \mathrm{~km}$ to the west of Homestead (EAST in Fig. 1). The S-Pol provided radar reflectivity and radial velocity fields every $5 \mathrm{~min}$ for this study. Both plan position indicator (PPI) and rangeheight indicator (RHI) displays were available.

The NCAR Multiple Antenna Profiler (MAPR) provided measurements of the horizontal and vertical wind components with a $30-\mathrm{s}$ time resolution and a $60-\mathrm{m}$ height resolution over a depth of $\sim 2.5-4.0 \mathrm{~km}$ (Cohn et al. 2001). MAPR has been found useful in another study of bores and solitons during IHOP_2002 (Koch et al. 2008). However, in the present case, MAPR seemed to lack the sensitivity needed to resolve the individual waves in the soliton as it passed through Homestead (though it did detect the leading updraft); for this reason, no MAPR data are shown herein, though some comparison with GLOW is made.

The NCAR Integrated Sounding System (ISS) at Homestead provided extremely detailed soundings every $3 \mathrm{~h}$. Wind data computed from GPS navigation signals received from the sonde were processed with a digital filter to remove low-frequency oscillations caused by the sonde pendulum motion beneath the balloon. In addition, the data were subjected to low-pass smoothing and automated quality control (QC) to remove suspect data points that did not pass tests for internal and vertical consistency, gross limit checks, and rate-of-change limits for temperature, pressure, and ascension rate.

Measurements of wind, moisture, and temperature fluctuations with temporal sampling ranging from 1 to $60 \mathrm{~min}$ were available from a collection of surface mesonetworks. Other remote sensing systems were in place at Homestead, but they were not used in the present study either because the systems were inoperative during this bore event or because they displayed insurmountable data problems on this day.

\section{Radar, surface mesonetwork, and DIAL analyses}

The origin of the bore was traceable to a cold outflow boundary from a mesoscale convective system in extreme western Kansas. The existence of the outflow boundary was made known by the appearance of a "fine line" in the Weather Surveillance Radar-1988 Doppler (WSR-88D) composite radar displays as early as 0036 UTC. The fine line was coincident with a pronounced convergence boundary between southeasterly flow ahead of the boundary and northerly or easterly winds behind it. The fine line propagated southeastward from a direction of $325^{\circ}$ at a speed of $15.7 \mathrm{~m} \mathrm{~s}^{-1}$ from 0036-0130 UTC (Fig. 2). This represents the velocity of the incipient density current $\left(\mathbf{C}_{\mathrm{dc}}\right)$. Evidence in support of the density current hypothesis is provided below.

As the density current expanded and weakened, it increasingly encountered a strong SBL and low-level jet. This interaction resulted in the generation of a bore by 0300 UTC, and soon thereafter, a solitary wave train became apparent (Fig. 3), because no discernible temperature contrast could be found across the boundary. The S-Pol detected five to seven waves with an average horizontal wavelength of $10.5 \mathrm{~km}$ as the soliton approached the Homestead vicinity (Fig. 4). The vertical structure of the soliton seen in RHI displays of reflectivity and radial velocity (Fig. 5) is indicative of trapped waves lacking any discernible vertical tilt in the lowest $2 \mathrm{~km}$ of the atmosphere. Because animation of these displays indicated that the waves did not propagate to the rear relative to the bore head, it is likely that they were of the trapped lee-wave form instead of the nonlinear wave disturbance explained by classical soliton theory.

Also apparent in these vertical cross sections is a very strong $\left(27 \mathrm{~m} \mathrm{~s}^{-1}\right)$ southerly jet riding along the top of the solitary wave train. The presence of this remarkably strong but shallow low-level jet had a huge influence on trapping solitary wave energy as shown in section 6 . Just above the jet at a height of $2.8 \mathrm{~km} \mathrm{AGL}$ there exists a sharp, undulating layer of higher reflectivity (white arrow). Animations of a sequence of these RHI images clearly indicated that the lifting of the strong low-level flow approaching the solitary wave train from the south (left-hand side of figure) generated this wavy filament.

The suggestion of wave trapping is strongly sup- 


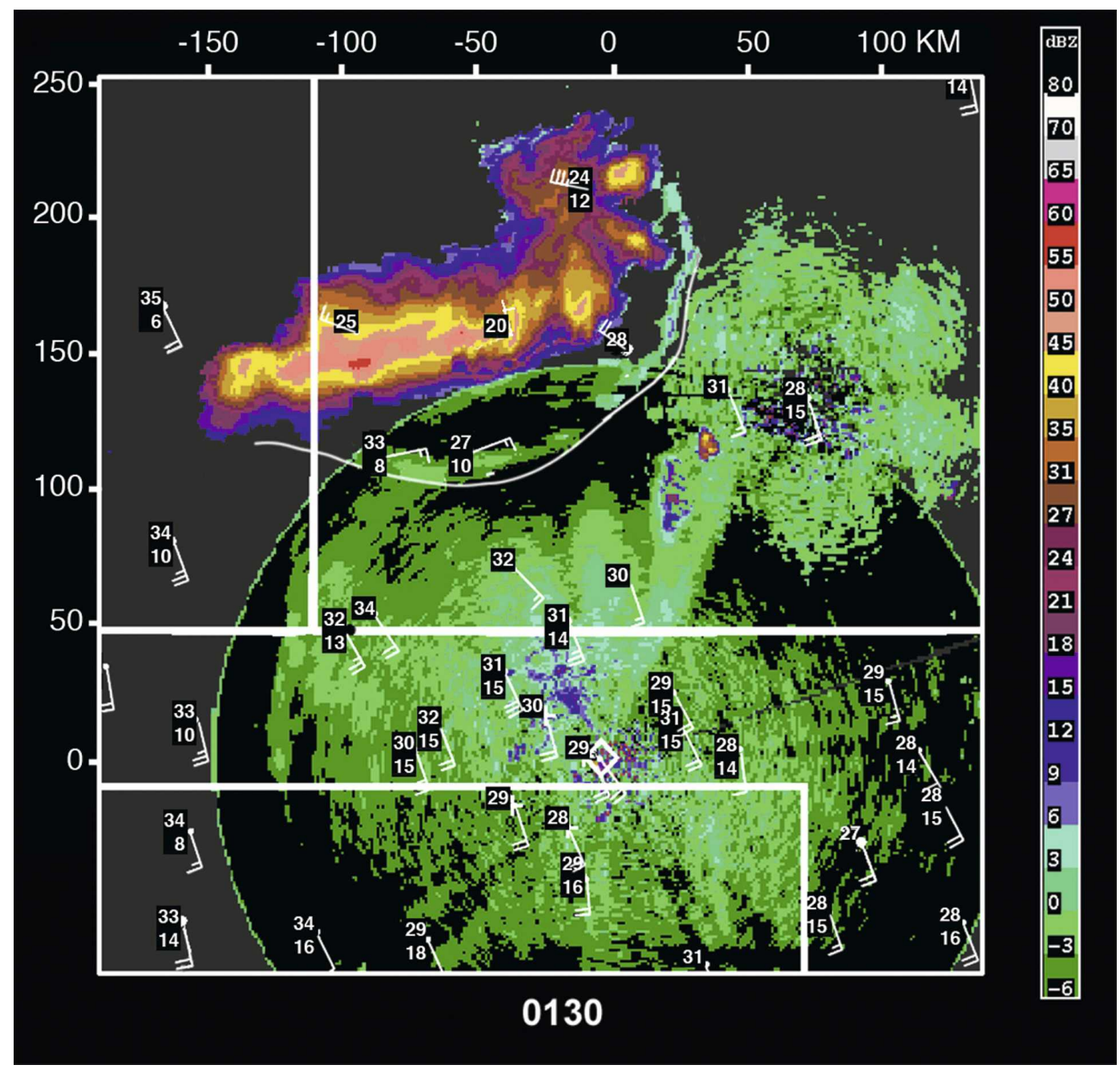

FIG. 2. Multiradar composite reflectivity display (dBZ) and surface mesonetwork plot [temperature and dewpoint $\left({ }^{\circ} \mathrm{C}\right)$ and winds, full barb $=5 \mathrm{~m} \mathrm{~s}^{-1}$ ] for 0130 UTC $20 \mathrm{Jun} 2002$. Radars used in the composite display consist of the WSR-88D radars in the area plus the S-Pol at Homestead (diamond). NCAR-Atmospheric Technology Division (ATD) high-resolution stations are highlighted by plus signs. The white line demarcates the edge of a convergence boundary originating from thunderstorms in western Kansas. This boundary evolved from a density current into the bore/soliton system.

ported by the Leandre II airborne DIAL measurements (Fig. 6). Whereas it is apparent that the soliton displayed pronounced changes with each successive aircraft pass through the system, the persistent lack of any discernible wave tilt with a height in the lowest $\sim 2.7 \mathrm{~km}$ of the atmosphere indicates sustained wave trapping. On the 0409-0427 UTC overpass (Fig. 6a), solitary waves with a horizontal wavelength of $15 \mathrm{~km}$ occur following the continuous rise in the height of the inversion layer from its undisturbed value of $0.8 \mathrm{~km}$ AGL (1.5 km MSL) to its displaced altitude of $1.4 \mathrm{~km} \mathrm{AGL}$ $(2.1 \mathrm{~km} \mathrm{MSL})$-values that are consistent with the 3-hourly soundings discussed in section 6a. Amplitude ordering of the waves is evident; that is, the leading wave displays the greatest amplitude. On the 0555-0616 UTC overpass (Fig. 6b), when the ground observing systems at Homestead intensively tracked the bore, perhaps the most striking of all the solitons during IHOP_2002 was seen. Approximately nine waves with a spacing of $11 \mathrm{~km}$ are present. Although these waves lack the amplitude ordering seen earlier, the inversion surface is lifted successively higher with each passing wave. The DIAL observations suggest that the flattening of the leading wave in the wave train relative to that seen on the earlier overpass may have brought about the demise of the soliton. Although this causality cannot be proven, if the first wave was flattened for whatever reason (leading to loss of amplitude ordering), 


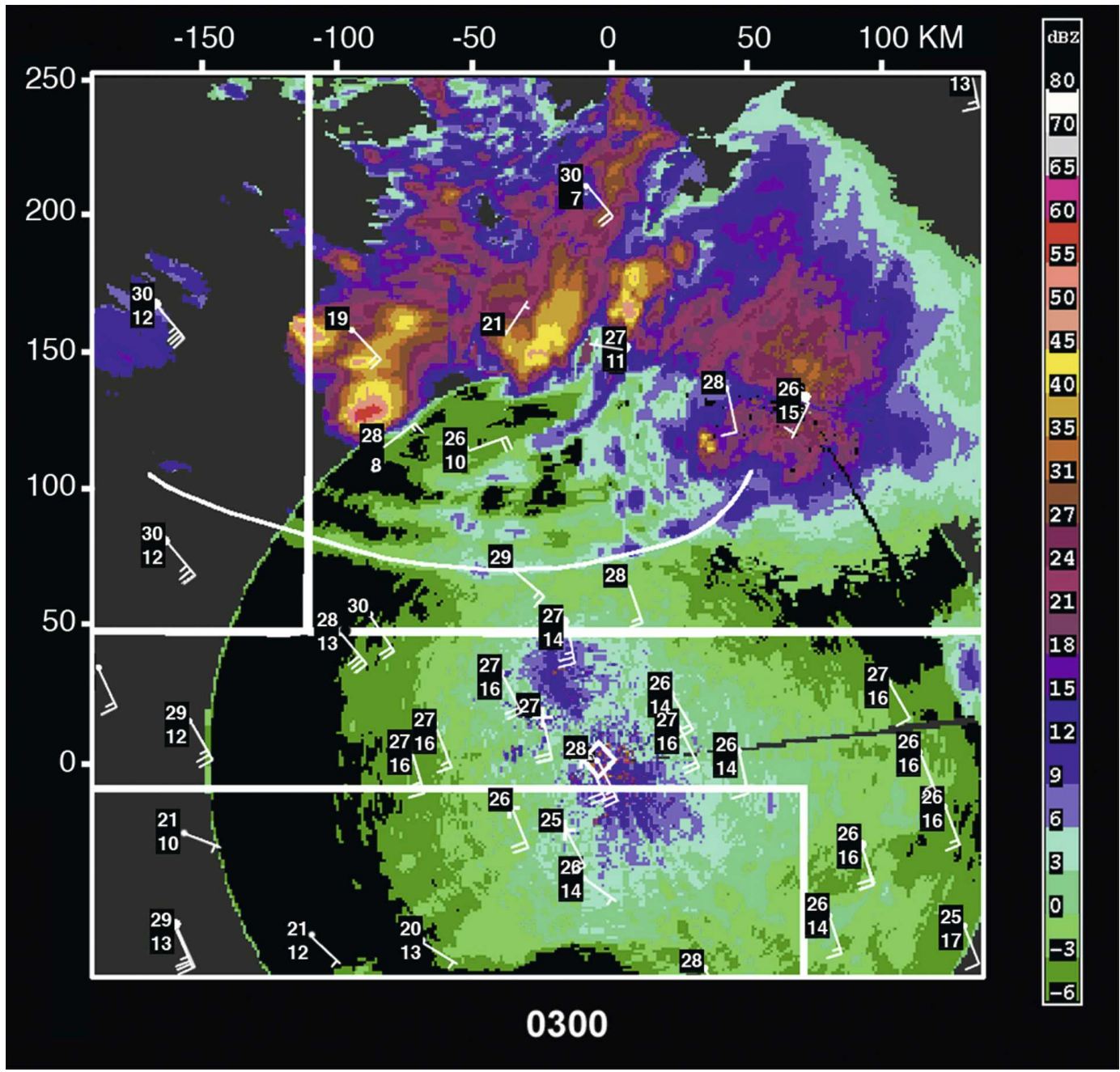

FIG. 3. Same as Fig. 2, but for 0300 UTC 20 Jun 2002. Note multiple parallel bands of higher reflectivity to the north of the convergence boundary, representing the soliton.

then the horizontal convergence supporting the lifting of the inversion surface must consequently have weakened, thereby leading to soliton demise.

Note in Fig. 6b the existence of mirrored oscillations at $2.7 \mathrm{~km}$ AGL (3.4 km MSL) in phase with those much lower and the presence of a strong vertical gradient of moisture in the 2.9-3.3-km layer preceding the soliton at 0409 UTC (Fig. 6a). This strong vertical moisture gradient suggests that Bragg scatter turbulent fluctuations may have been the cause of the radar-observed thin filament. The oscillatory features in these DIAL data collectively represent a moist, nearly saturated layer induced by the lifting at lower levels. It appears that S-Pol and Leandre II DIAL were detecting the same filament, but because the radar and lidar measure different properties of the atmosphere, the filament appears more continuous in the radar (Bragg scatter in the layer of enhanced moisture gradient) and more oscillatory or discontinuous in the lidar (which is sensitive to the locally enhanced moisture at this level caused by the solitary wave lifting). These features cannot be clouds because there is no evidence in the DIAL data of significant signal attenuation, nor did the Homestead surface infrared radiation data show any evidence of fluctuations near the time of bore passage. Because the layer was nearly saturated, the oscillatory features may be thought of collectively as a haze layer.

Time traces of assorted variables derived from the 15-min resolution southwest Kansas mesonetwork data (Fig. 7) show how the density current characteristics quickly evolved into a purely bore character. At station SW7, located in northwestern Kansas, a sharp $11^{\circ} \mathrm{C}$ drop in temperature accompanied a pronounced 10 $\mathrm{m} \mathrm{s}^{-1}$ decline in the bore-relative component of the 


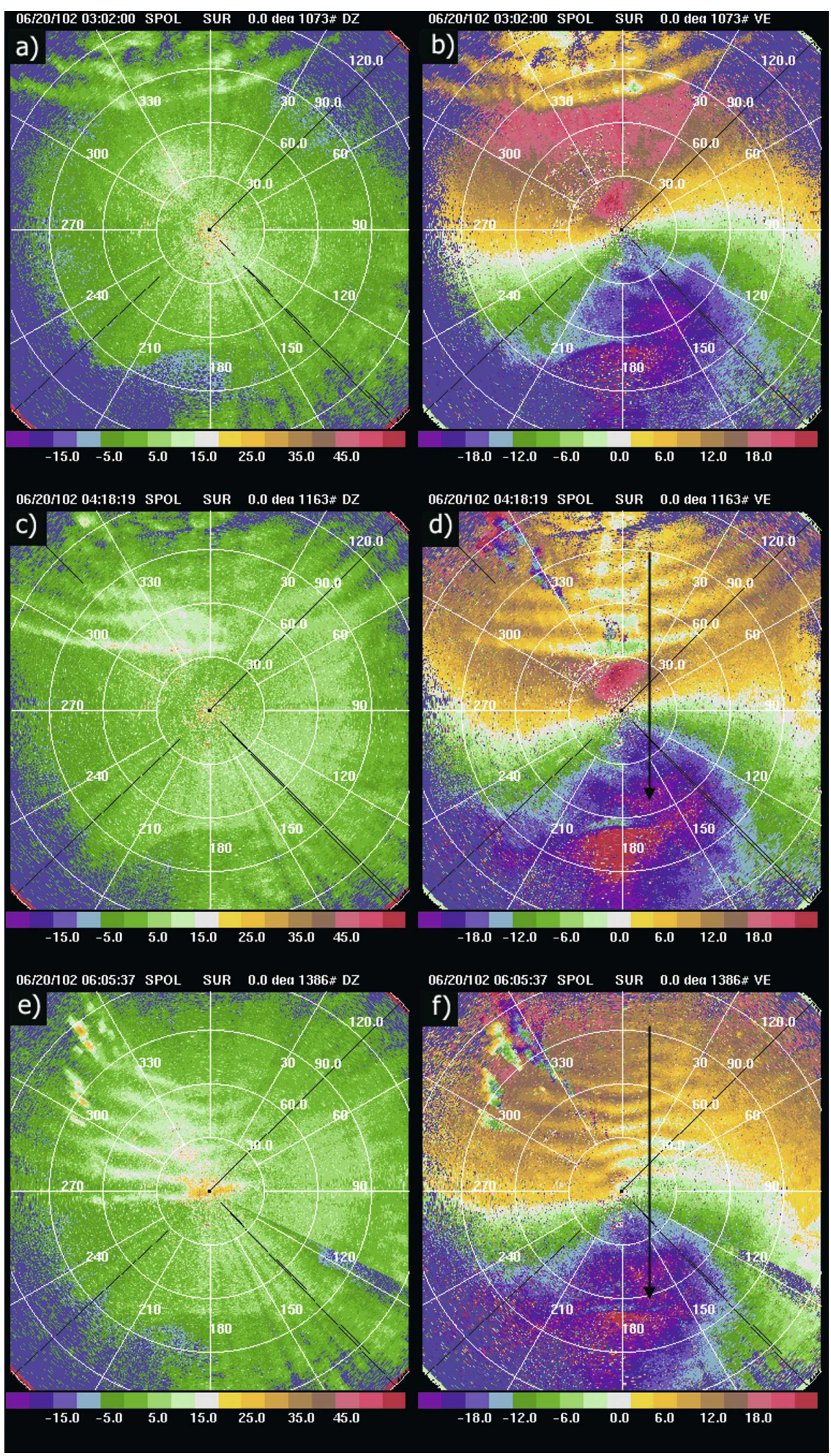

FIG. 4. Bore and trailing solitary wave train at $0302 \mathrm{UTC}$ as seen in S-Pol $0^{\circ}$ elevation angle scan of (a) reflectivity $(\mathrm{dBZ})$ and (b) radial velocity $\left(\mathrm{m} \mathrm{s}^{-1}\right.$, positive outbound, negative inbound). Compare this more detailed display to the composite radar display for this same time in Fig. 3. (c), (d) Same as (a), (b), but at 0418 UTC, which is approximately midway through the 0409-0427 UTC north-south leg of the P-3 aircraft (Leandre II, black arrow). (e), (f) Same as (a), (b), but at 0605 UTC, which is approximately midway through the 0555-0617 UTC north-south leg of the P-3. Range rings are at 30-km spacing. 


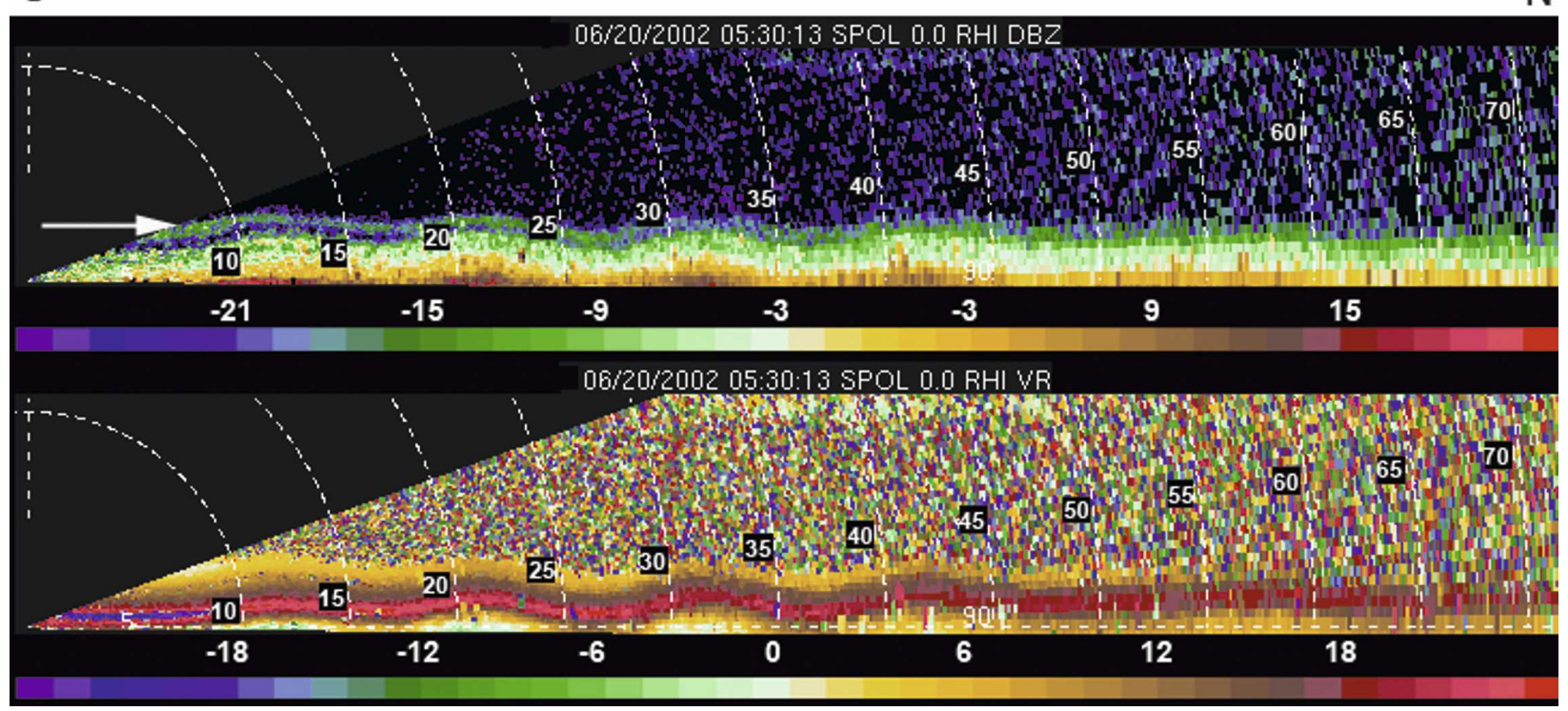

FIG. 5. RHI displays along the $360^{\circ}$ azimuth at 0530 UTC of (top) S-Pol reflectivity (dBZ) and (bottom) radial velocity [m s ${ }^{-1}$; positive (negative) values are winds directed to the north (south) away from (toward) the radar]. The vertical structure of the solitary wave train and the very strong $\left(27 \mathrm{~m} \mathrm{~s}^{-1}\right)$ low-level southerly jet at a height $<1 \mathrm{~km}$ AGL are evident. Horizontal wavelength of the soliton is $10.5 \mathrm{~km}$ (dashed white lines indicate range from the radar). At this time, the leading edge of this wave train was $9 \mathrm{~km}$ to the north of S-Pol; given the observed bore speed of $6.2 \mathrm{~m} \mathrm{~s}^{-1}$, this provides an estimated time of arrival of 0554 UTC at the radar. The white arrow points to an overlying layer of higher reflectivity that was induced by lifting over the bore head.

winds normal to the direction of propagation of the boundary. An isochrone analysis of the movement of the boundary as detected both by a fine line seen in the radar composite displays and by the high-resolution surface pressure perturbation traces (Fig. 8) shows that the phase velocity of the boundary was $\mathbf{C}_{b}=325^{\circ}, 15.7$ $\mathrm{m} \mathrm{s}^{-1}$ during the period of time that pronounced cooling attended the convergence boundary. The next station affected by the passage of this boundary (SW8) recorded a much weaker convergence feature and cooling (Fig. 7). By the time the boundary had progressed to the Oklahoma Panhandle near station SW9, no cooling was discernible, although a pronounced wind shift was still present (these are both characteristics of a bore). Although the temperature and wind changes accompanying the density current and later the bore were pronounced, the lack of high-resolution pressure data in western Kansas (only hourly data were available) made it impossible to follow the progression of any associated pressure pattern.

As the bore evolved into a packet of solitary waves and propagated toward the Homestead region in the Oklahoma Panhandle, its speed of propagation decreased to $6.2 \mathrm{~m} \mathrm{~s}^{-1}$. In this region, 1-5-min-resolution mesonetwork data (including pressure measurements) were available (Fig. 9). HOOK observed a wavelike pressure perturbation phenomenon (where "perturba- tion" is the difference from the value at the time of pressure jump, i.e., at 0410 UTC in this case). The winds display a quarter-wavelength (quadrature) phase-lag relationship to the pressure waves, which is characteristic of solitary (gravity) waves. As the soliton progressed to the location of the S-Pol at station EAST, the wavy pressure pattern appeared to have broadened, although the quadrature relationship was maintained (Figs. 9b,d). The longer period is largely attributable to the deceleration in the propagation speed of the bore/ soliton.

\section{Doppler lidar analysis}

The GLOW Doppler lidar provided very detailed measurements allowing for determination of the twodimensional vertical circulation accompanying the dissipating soliton as it passed over the Homestead facility. We describe first the QC procedures used with this data, then the methodology for obtaining the desired circulation system, and finally the results.

\section{a. Error analysis}

A basic characteristic of direct-detection Doppler lidar is that the accuracy degrades as the inverse square root of the detected signal counts (level), or, equiva- 
a)

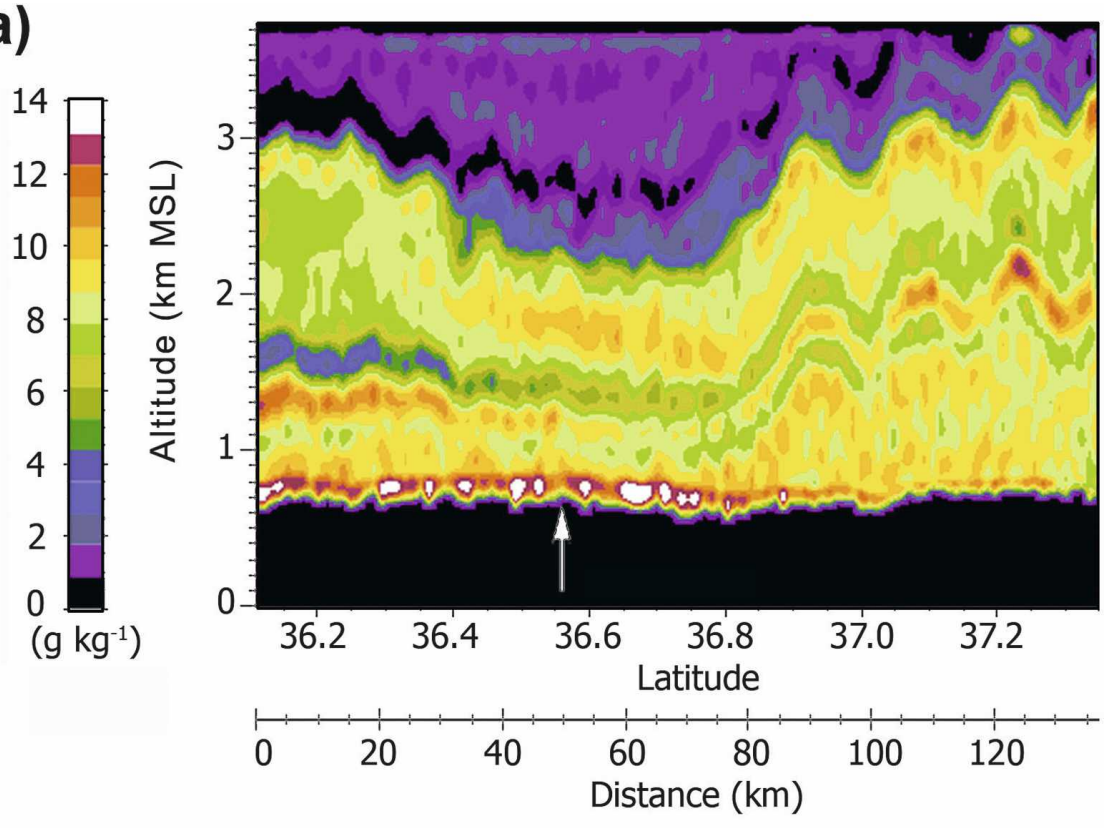

b)

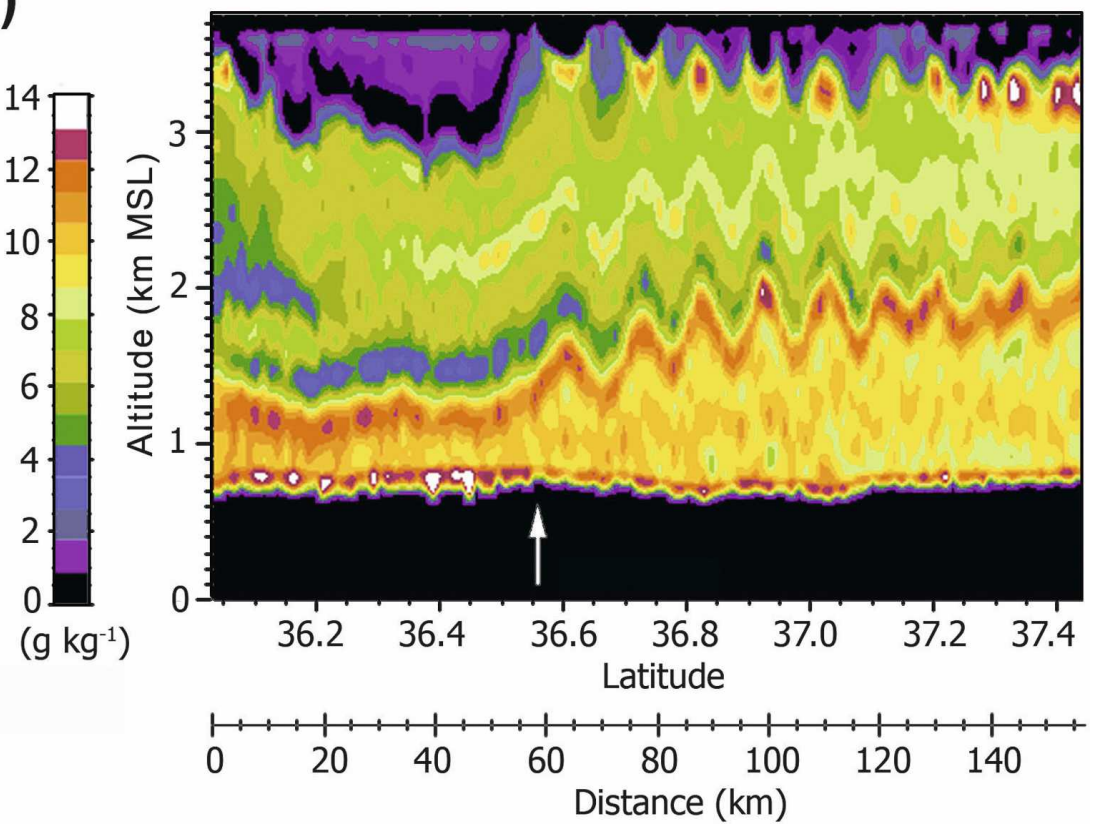

FIG. 6. Vertical cross sections of water vapor mixing ratio $\left(\mathrm{g} \mathrm{kg}^{-1}\right)$ acquired by the Leandre II DIAL system on two successive north-south legs of the P-3 aircraft through the bore/soliton system at (a) 0409-0427 UTC and (b) 0555-0617 UTC. The plane flew southward (from right to left in this display) at a constant altitude of $4.5 \mathrm{~km}$ MSL ( $3.8 \mathrm{~km} \mathrm{AGL})$. The location of Homestead is shown by a white arrow. Waves on the earlier leg display amplitude ordering: the first wave has the strongest amplitude and lifts the low-level inversion surface from its original level of 0.8 to $1.4 \mathrm{~km}$ AGL (1.5 to $2.1 \mathrm{~km} \mathrm{MSL}$ ). At least eight waves with a horizontal wavelength of $11 \mathrm{~km}$ are apparent on the later leg, but lack amplitude ordering (they all display a crest-to-trough amplitude of $0.6 \mathrm{~km}$ ). Lifting by the soliton apparently creates an oscillatory, nearly saturated layer at $2.7 \mathrm{~km}$ AGL (3.4 km MSL) on this leg. Note the lack of any discernible wave tilt with height through $3.4 \mathrm{~km}$ MSL on both flight legs. 
a)

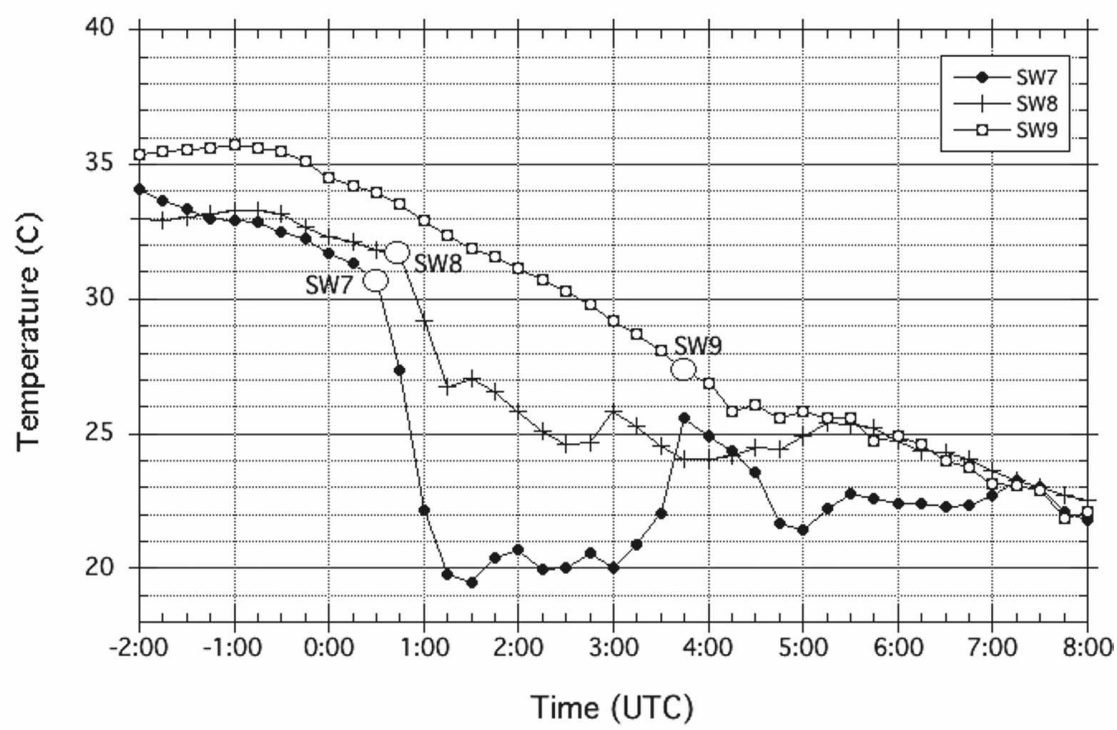

b)

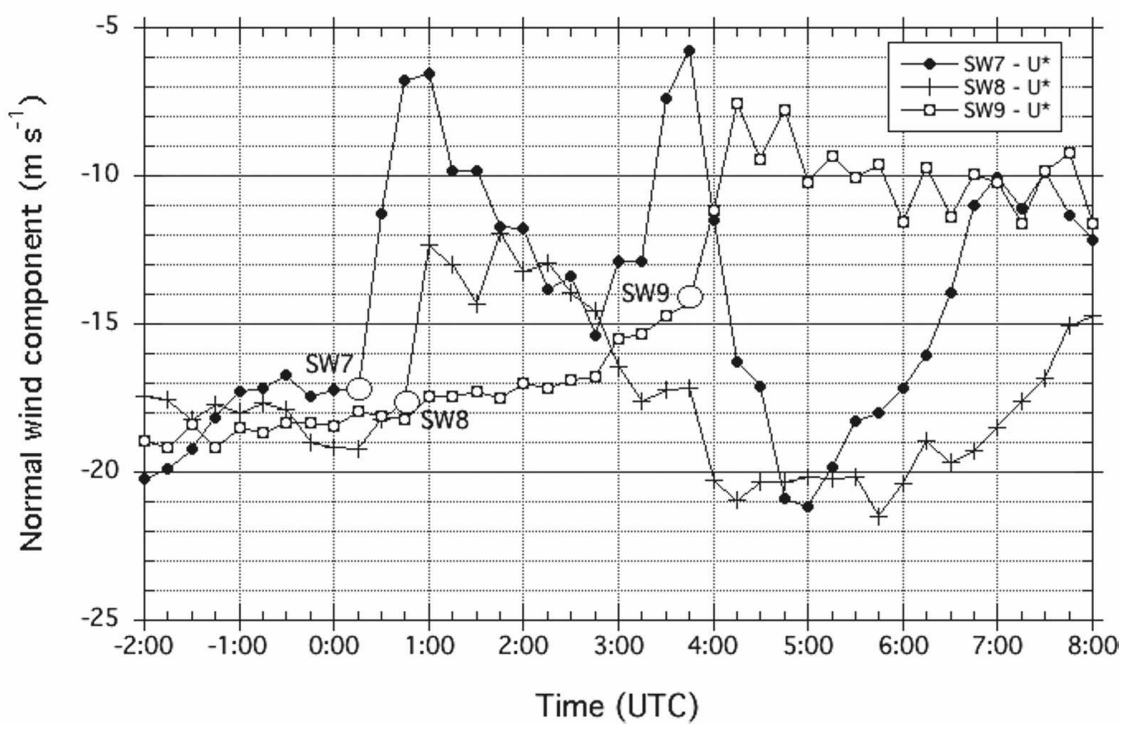

FIG. 7. Time series of (top) temperature $\left({ }^{\circ} \mathrm{C}\right)$ and (bottom) bore-relative normal wind component $\left(\mathrm{m} \mathrm{s}^{-1}\right)$ from mesonet stations SW7, SW8, and SW9 in southwestern Kansas (locations shown in Fig. 1). Circles denote the times that convergence boundaries passed overhead. The trace from SW7 shows the boundary when it displayed characteristics of a density current, notably the rapid $11^{\circ} \mathrm{C}$ cooling and sudden decrease in the bore-relative southerly winds. Much less cooling and weaker convergence occurred at SW8. By the time the boundary reached SW9, cooling had ended because by then the bore had been generated from the density current.

lently, the range (altitude). Random errors in the derived wind speed and direction were calculated by propagating the detected signal shot noise through the wind algorithm (Gentry and Chen 2002). There is no fundamental velocity resolution imposed by the instru- ment design or signal processing electronics (e.g., detector bandwidth, digitizer sample rate and length, FFT parameters), as there would be in a Doppler radar or heterodyne Doppler lidar. In essence, the shot noiselimited velocity error represents the fundamental limit 


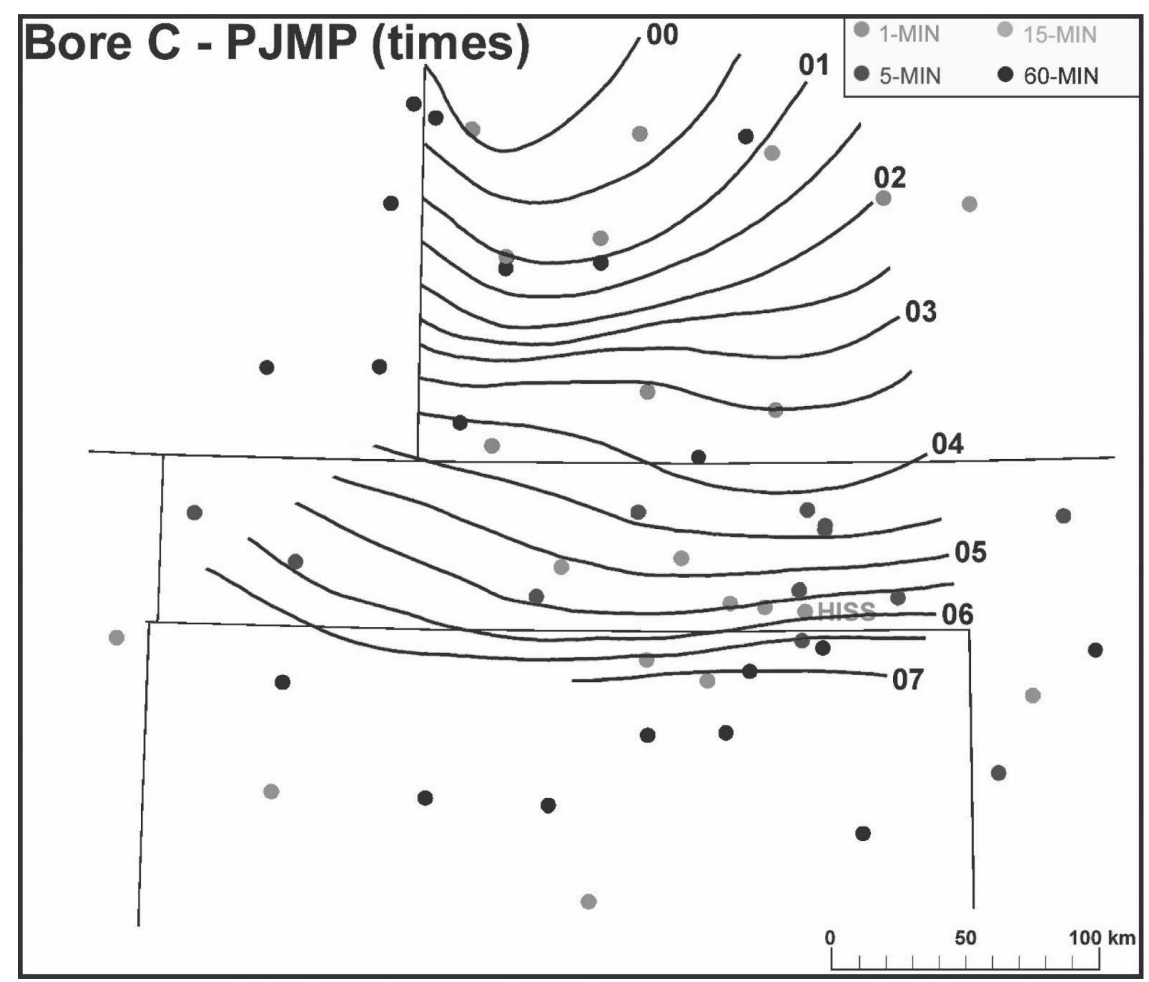

FIG. 8. Half-hourly isochrone analysis of the leading radar fine line and the accompanying wind shift associated with the density current (0000-0200), bore (0200-0430), and soliton (0430-0700 UTC). From this analysis, the density current and bore propagation velocities of $\mathbf{C}_{\mathrm{dc}}=325^{\circ}, 15.7 \mathrm{~m} \mathrm{~s}^{-1}$ and $\mathbf{C}_{b}=350^{\circ}, 6.2 \mathrm{~m} \mathrm{~s}^{-1}$ were obtained.

to the velocity resolution. This method has been shown to agree quite well with the standard deviation calculated from the means of individual wind profiles, at least in stable boundary layer situations (which are relevant to bore events).

For the purpose of performing QC, the threshold noise level was determined by taking the inverse square root of the sum of the photon counts at the first (lowest) occurrence of either a speed error $>5 \mathrm{~m} \mathrm{~s}^{-1}$ or a direction error $>50^{\circ}$ for each profile and then taking the average of those values. The reason for selecting these values for wind speed and direction error thresholds is that they produced the most agreeable qualitycontrolled winds. The ratio of wind speed to random error is shown in Fig. 10a and the wind direction random error is displayed in Fig. 10b. The horizontal wind vectors prior to and after QC postprocessing (Fig. 10c) show that useful data were available below $\sim 2.3 \mathrm{~km}$ AGL.

The quality-controlled signals from GLOW were processed to determine the $u$ and $v$ wind components under the assumptions of spatial homogeneity of the horizontal wind field at any given altitude over the sampled area and negligible vertical wind. Although these assumptions are not strictly correct with respect to sampling the solitary waves (as shown below) because the average wave period was $>15 \mathrm{~min}$, horizontal homogeneity was nonetheless approximately valid over the 3.5-min sampling interval for GLOW. Also, even though the vertical velocities were typically 1.0 $2.5 \mathrm{~m} \mathrm{~s}^{-1}$, they did not map to the horizontal velocities in a significant way because of the small elevation angle used by GLOW. Given a lidar elevation angle of $30^{\circ}$, the vertical velocity component projected to the radial velocity is $v_{r}=w \sin \left(30^{\circ}\right)=0.5 w$. Hence, about half the local vertical velocity will be measured in each radial wind observation. Because the magnitude of the horizontal winds was $15-20 \mathrm{~m}, \mathrm{~s}^{-1},<8 \%$ of the total radial wind speed is attributable to the vertical motion effect.

\section{b. Vertical circulation analysis methodology}

The technique used to derive the two-dimensional vertical circulation in the plane of the propagating bore/ soliton system from the Doppler lidar wind analysis is similar to methods developed by the lead author in previous studies of bores and gravity waves using wind profiler data (Koch and Clark 1999; Trexler and Koch 
a)

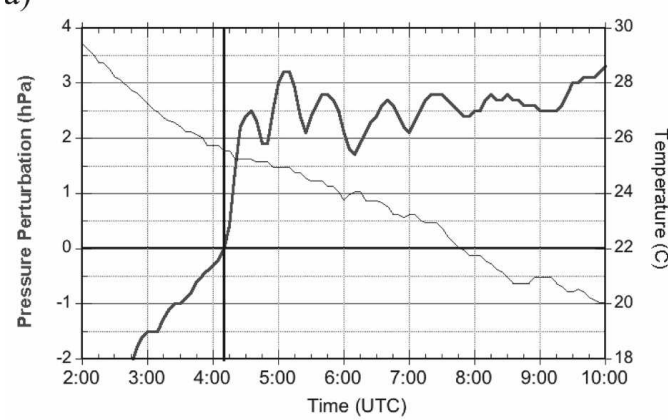

c)

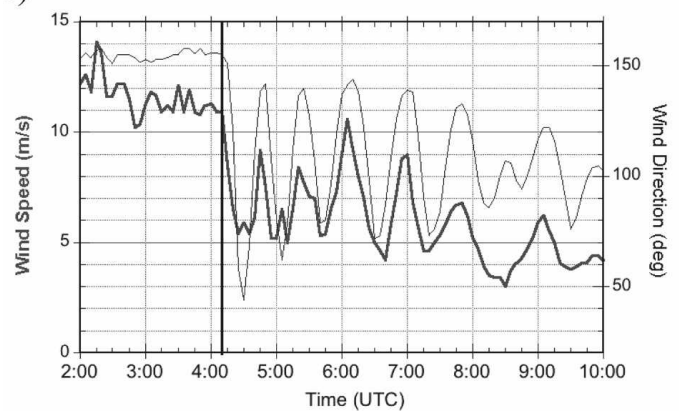

b)

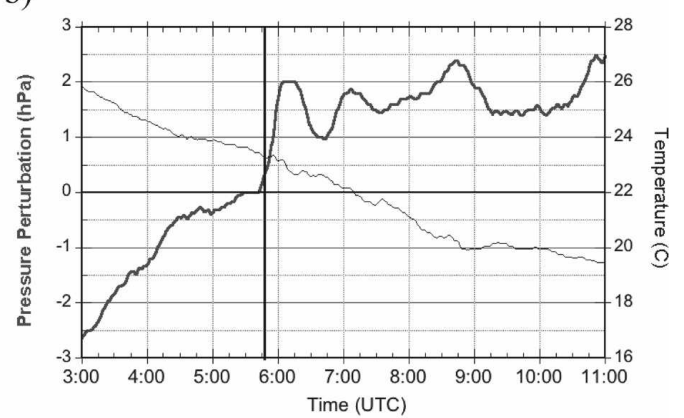

d)

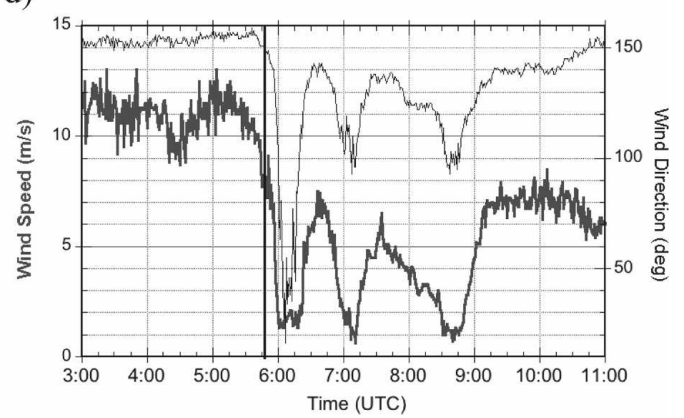

FIG. 9. Time series of (a) temperature (thin line, ${ }^{\circ} \mathrm{C}$ ) and pressure perturbation (hPa, thick line) from HOOK, (b) temperature and pressure perturbation from EAST, (c) wind speed (thick line, $\mathrm{m} \mathrm{s}^{-1}$ ) and direction (thin line,$^{\circ}$ ) from HOOK, and (d) wind speed and direction from EAST (locations shown in Fig. 1). Vertical black lines denote times of bore passage defined by pressure jump. Note the quarter-wave phase lag between pressure and wind perturbations following bore passage, associated with the solitary waves, a characteristic of gravity waves, and how the wave period lengthened as the bore propagated southeastward and weakened from HOOK to EAST.

2000). The basic underlying assumptions are that (i) only the wind component perpendicular to the bore (the "bore-normal" wind) is important for estimation of the horizontal divergence and (ii) time-to-space transformation can be used with the lidar time-height data given accurate information about the propagation speed of the bore/soliton system. These assumptions can be expressed mathematically as

$$
\boldsymbol{\nabla} \cdot \mathbf{V} \cong \frac{\partial U^{*}}{\partial x^{*}}=C_{b}^{-1} \frac{\partial U^{*}}{\partial t},
$$

where $U^{*}$ is the bore-normal wind component in the $x^{*}=350^{\circ}$ plane, $C_{b}$ is the bore propagation speed in the Homestead vicinity $\left(6.2 \mathrm{~m} \mathrm{~s}^{-1}\right)$, and $\Delta t=3.5 \mathrm{~min}$ (thus, $\Delta x=1.3 \mathrm{~km})$.

Prior to performing the time-to-space transformation, and following the QC procedure described in section $5 \mathrm{a}$, the GLOW data were rotated into the bore reference frame, from which the bore-relative winds $\left(U^{*}-C_{b}\right)$ were calculated. This procedure resulted in the generation of a uniform, two-dimensional space-height grid of values from $z_{0}=75 \mathrm{~m} \mathrm{AGL} \mathrm{up} \mathrm{to} z_{t} \sim 2325 \mathrm{~m}$ AGL, where the QC criteria were most often violated
(Fig. 10c). Vertical velocities were computed by upwardly integrating the Boussinesq mass continuity equation from $z_{0}$ to $z_{t}$ under the assumption that $w=0$ at $z_{0}$, as shown here:

$$
w\left(z_{2}\right)=w\left(z_{1}\right)-\sum_{z_{1}}^{z_{2}} \frac{\Delta U^{*}}{\Delta x^{*}} \Delta z .
$$

This simple kinematic procedure for estimating vertical motion from Doppler wind data is well known for being problematic if extended too far upward because errors in the horizontal wind estimates accumulate with height. More sophisticated techniques, such as the O'Brien correction method [used with wind profiler data by Trexler and Koch (2000)] and variational adjustment methods [used in dual-Doppler radar analysis by Koch et al. (1993)], can be applied if needed. However, we are only integrating the GLOW data through a shallow $\sim 2-\mathrm{km}$ depth, and the variational method necessitates an arbitrary assumption about the upper level at which vertical motion is assumed to be nonexistent. Therefore, these other methods are neither necessary nor even desirable. 

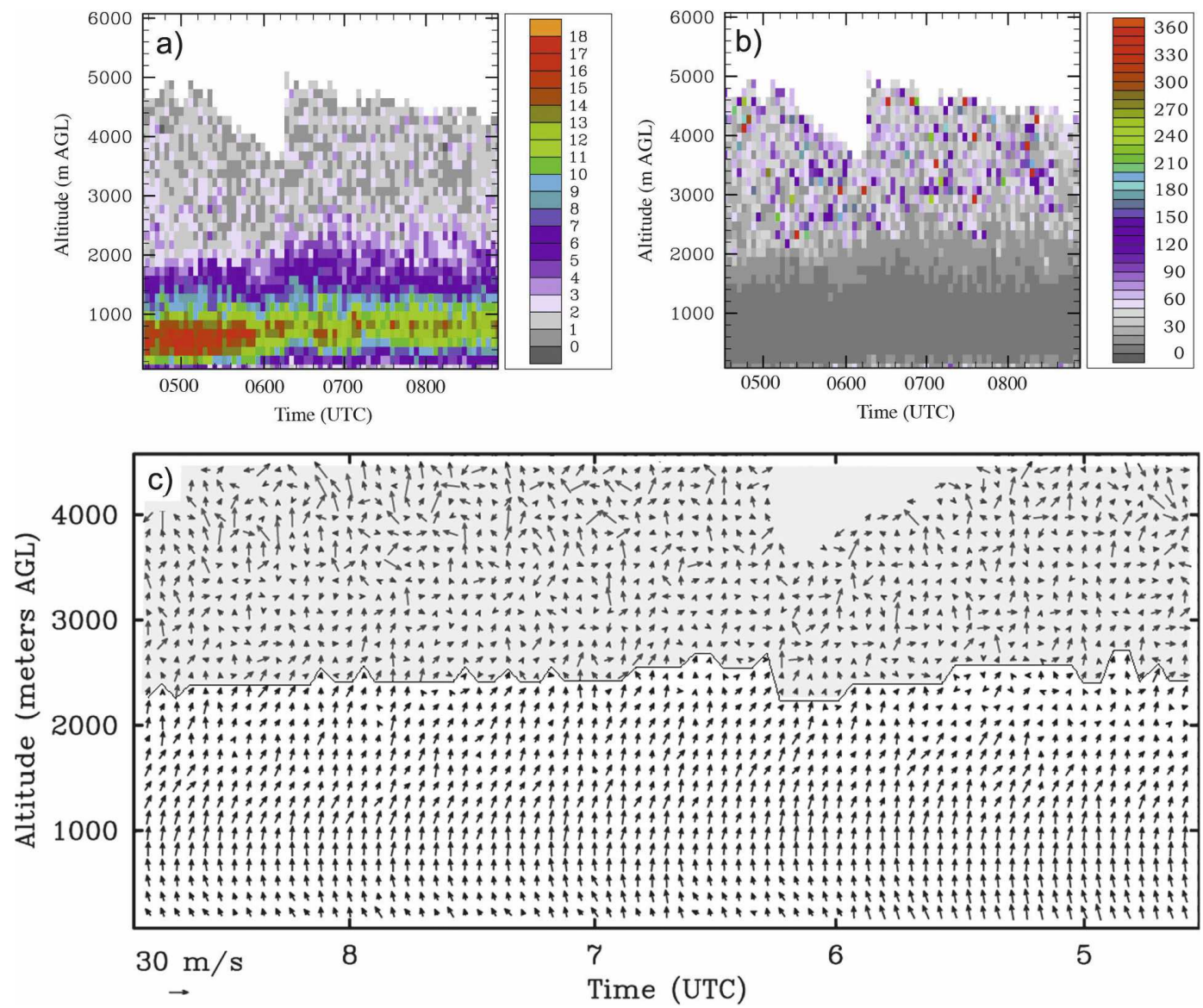

FIG. 10. (a) Ratio of the measured wind speed to the estimate of wind speed random error obtained from GLOW data for the period 0432-0852 UTC; (b) wind direction $\left(^{\circ}\right.$ ) random error estimate for the same period; and (c) horizontal wind vectors (note time scale is inverted, so that events preceding the bore occur to the right). Wind estimates exceeding the threshold noise level are shaded in gray in (c) above the broken line, where the threshold is defined as the inverse square root of the sum of the photon counts at the first (lowest) occurrence of either a speed error $>5 \mathrm{~m} \mathrm{~s}^{-1}$ or a direction error $>50^{\circ}$ for each profile.

\section{c. Vertical circulation of the soliton}

The bore/soliton-relative winds and derived vertical motions were combined to produce the vertical circulation system displayed in Fig. 11 (vertical motions are magnified by a factor of 10 to highlight features in Fig. 11a, but not in Fig. 11b). The success of this technique in deriving the up-and-down circulation system of the solitary wave train is apparent for several reasons. First, seven or eight updraft and downdraft couplets are resolved, similar in number to those seen in both the S-Pol (Fig. 4f) and DIAL displays (Fig. 6b). Second, the first significant updraft is found precisely at the time that the bore passed over the GLOW facility (0613 UTC, or $X=0 \mathrm{~km}$ following time-to-space conversion). The term "significant" refers to a feature whose depth extends throughout most of the lower $2 \mathrm{~km}$ of the atmosphere, as opposed to the irregular, shallow fea- tures seen ahead of the first solitary wave. Also, MAPR vertical motions (not shown) of $\sim 1.5 \mathrm{~m} \mathrm{~s}^{-1}$ in a layer from $1.0-2.3 \mathrm{~km}$ agree well with the derived GLOW values. Third, a high correlation between the abrupt ramping up in the depth of high GLOW photon counts (shading in Fig. 11a) and the time of the first significant updraft (Fig. 11b) further substantiates the veracity of this vertical circulation analysis. The GLOW photon counts increased dramatically (by as much as $90 \%$ over background values) over a 6 -min period commencing precisely at the time of bore passage. The increases were present throughout the entire $2.7-\mathrm{km}$-deep bore layer, but also above this layer because of induced lifting by the bore. The likely cause of this extremely rapid increase in GLOW signal strength is increased aerosol backscatter attending the bore passage, assuming that there is a significant correlation between aerosol backscatter and the water 


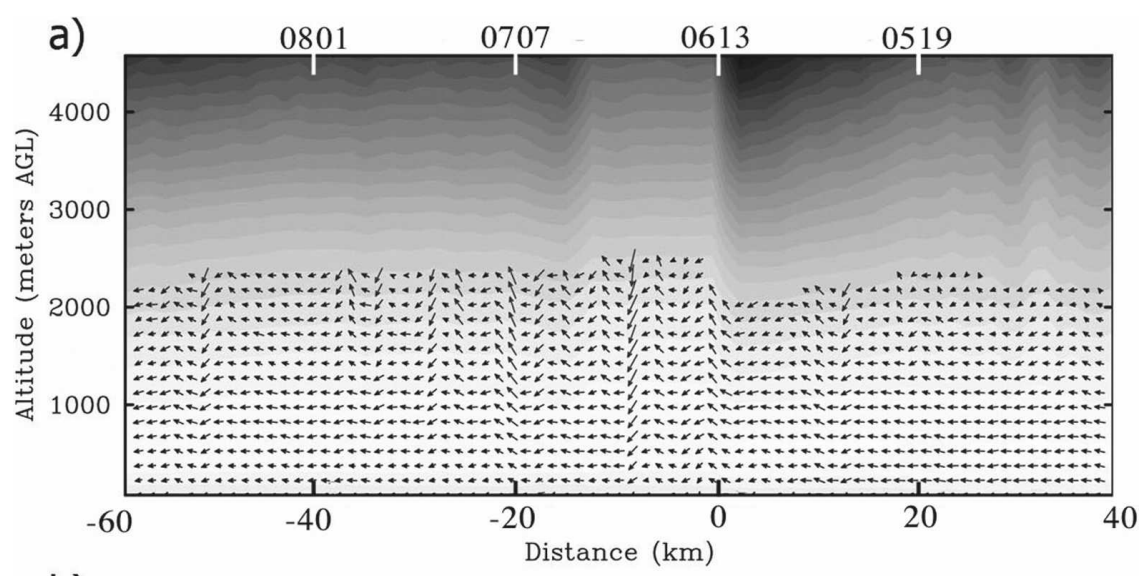

b)

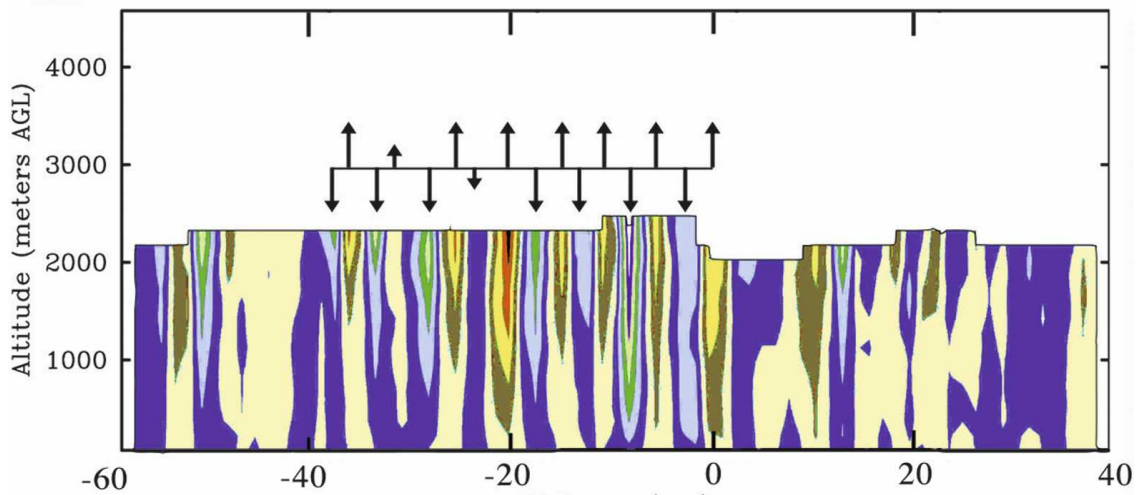

Distance $(\mathrm{km})$

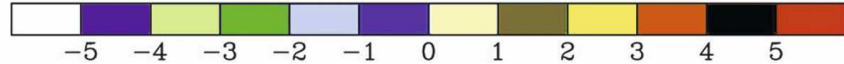

FIG. 11. (a) Two-dimensional vertical circulation transverse to the bore obtained from analysis of the GLOW data using the technique as described in the text. Vertical motions have been magnified by a factor of 10 to highlight the circulation system. Shading represents average photon count values [the signal-to-noise ratio (SNR) measure], with darker shades being the weakest values. Note the ramp-up in SNR values at $X=0 \mathrm{~km}$, corresponding to the time the bore passed the lidar (0613 UTC). (b) Color contour analysis of derived vertical velocities $\left(\mathrm{m} \mathrm{s}^{-1}\right)$ with updrafts and downdrafts accompanying the bore and solitary wave family highlighted with up-down arrows whose length is shorter for amplitudes weaker than $1 \mathrm{~m} \mathrm{~s}^{-1}$. The average wavelength of these features is $5.8 \mathrm{~km}$.

vapor increase seen at the same time by the Leandre II DIAL.

There is, however, a notable incongruity between the horizontal wavelength of the vertical motions seen in the SPOL and DIAL displays $(10-11 \mathrm{~km})$ and those resolved in the GLOW analysis (5.8 $\mathrm{km}$ on average). One possible explanation might be that the wrong advection velocity was used in the time-to-space formulation. If this were the case, however, a speed of twice the value selected would need to have been used, which is unreasonable. Another possibility is that perhaps we are attempting to obtain irresolvable information from the 3-min resolution GLOW data, resulting in aliased results. However, the $5.8-\mathrm{km}$ wavelength is equivalent to a 16 -min periodicity $(5-6 \Delta t)$, which is fully resolvable using the kinematic method to obtain the vertical motions. Yet another possibility to consider is that the results are just meaningless noise. However, there are too many other arguments, both those offered above and those to follow, against such an explanation.

None of the above explanations for the incongruity is satisfactory. In support of our contention that the GLOW results are valid, it is significant that the discrepancy in horizontal wavelength is a factor of $\sim 2$. This suggests the hypothesis that GLOW may have been resolving a subharmonic wave disturbance not detected by the other two remote sensing systems. Close examination of the Leandre II cross section at the time 
of passage of the soliton over Homestead (Fig. 6b) does reveal a weak, smaller-scale wave component at distances beyond $130 \mathrm{~km}$, where wavelengths of $6-7 \mathrm{~km}$ are present. It is quite possible that the largeramplitude features with wavelengths of $10-11 \mathrm{~km}$ masked the presence of the smaller waves except at the longer ranges from the bore head, where the longer waves were weaker.

Additional evidence offered in support of the validity of these results is that layer displacements computed using the derived GLOW vertical motions are in excellent agreement with those implied by the changes in height of the Leandre II mixing ratio surfaces. The method we used to determine the wave-induced layer displacements from the GLOW results was to create a mathematical representation of the time-height vertical motion field $W(z, t)$ and then temporally integrate this function to find the wave-displacement function profile $\zeta(z)$. The vertical motion profile for the soliton was represented by a cosine function below the level of maximum vertical velocity (linearly decreasing to zero above that level to $z=2.8 \mathrm{~km}$ ),

$$
W(z, t)=\hat{W}\left\{\cos \left[\frac{2 \pi\left(z-z_{0}\right)}{H}\right]\right\}^{1 / 2} \cos \left[\frac{2 \pi\left(t-\tau_{0}\right)}{T}\right],
$$

where $\hat{W}$ is the maximum upward motion value for the solitary waves, $z_{0}$ and $t_{0}$ are the height and time, respectively, of maximum wave upward motion, $H$ is the depth of the bore, and $T=16 \mathrm{~min}$ is the solitary wave period. Upon temporally integrating (5) over the wave period, we obtain the soliton displacement function

$$
\zeta(z)=\frac{T}{\pi} \hat{W} \cos \left[\frac{2 \pi\left(z-z_{0}\right)}{H}\right]^{1 / 2} .
$$

A scatterplot of the vertical velocity maxima in each vertical data column (Fig. 12a) and a histogram of the height of the vertical velocity maxima (Fig. 12b) suggest these representative values for the solitary wave updrafts: $\hat{W}=2.3 \mathrm{~m} \mathrm{~s}^{-1}$ and $z_{0}=2.2 \mathrm{~km}$. Insertion of these values into (6) produces maximum displacements of $\zeta(z)=0.4-0.7 \mathrm{~km}$ in the $0.4-2.5-\mathrm{km}$ layer. This agrees well with the changes in height of the Leandre II mixing ratio surfaces (Figs. 6a,b).

\section{Sounding and hydraulic theory analyses}

If some mechanism is not present to trap the upward leakage of wave energy, bores cannot be maintained very long in a stratified atmosphere (Crook 1988). Wave trapping ability is typically measured by the vertical wavenumber, defined as
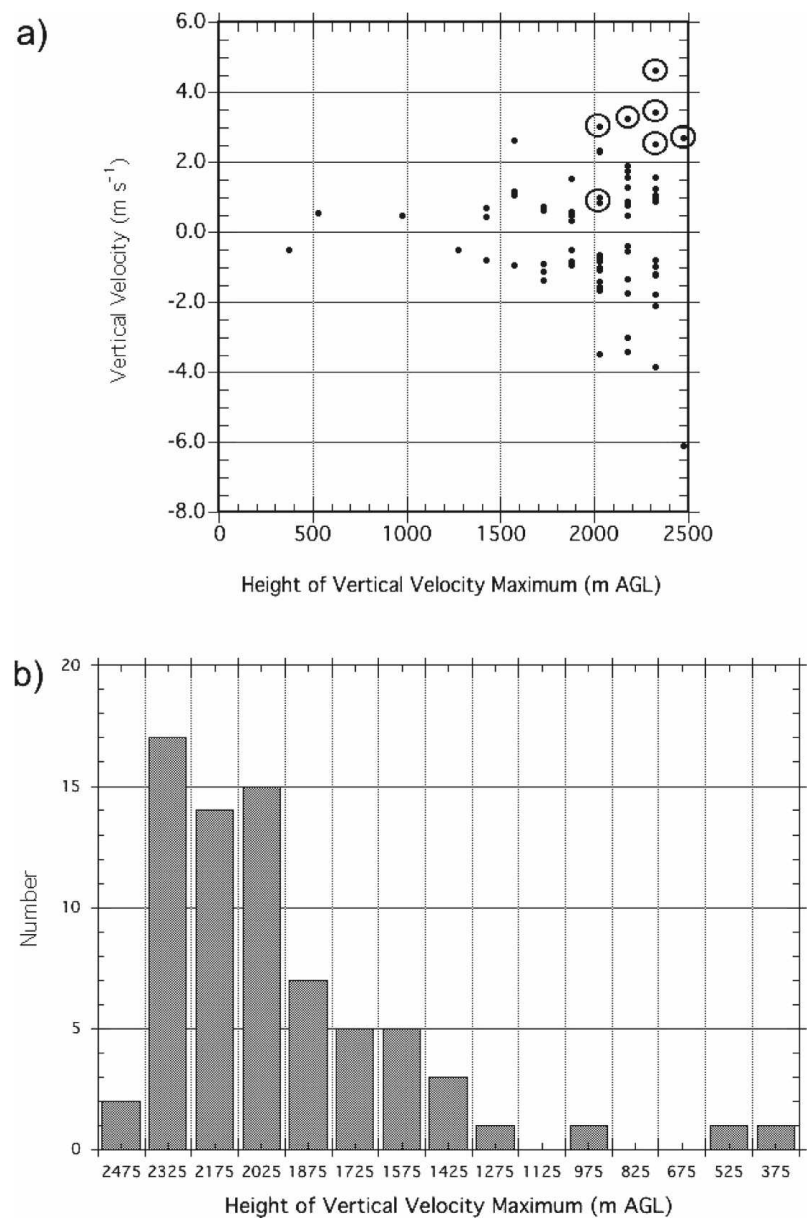

FIG. 12. Statistical summary of vertical velocity analysis using GLOW data: (a) the maxima in each vertical column as a function of the height of the vertical velocity maxima (m AGL) and (b) a histogram of the height of the vertical velocity maxima. Circled points in (a) depict values corresponding to solitary wave updrafts.

$$
m^{2}=\frac{N_{m}^{2}}{\left(U^{*}-C_{b}\right)^{2}}-\frac{\partial^{2} U^{*} / \partial z^{2}}{\left(U^{*}-C_{b}\right)}-k^{2},
$$

where $k$ and $m$ are the horizontal and vertical wavenumbers and $N_{m}$ is the moist Brunt-Väisälä frequency computed using the virtual potential temperature. The Scorer parameter is identical to $m$ when $k^{2}$ is negligible; the discussion to follow will use this terminology because $k^{2}$ was excluded in all calculations. A rapid decrease of the Scorer parameter with height supports wave trapping, particularly if it becomes negative. This can arise because of the presence of a strong inversion, especially if wind speed increases with height [this "stability" term is the first in (7)]. However, the strong curvature associated with the low-level jet (the second term) appears to be the most effective mechanism for 


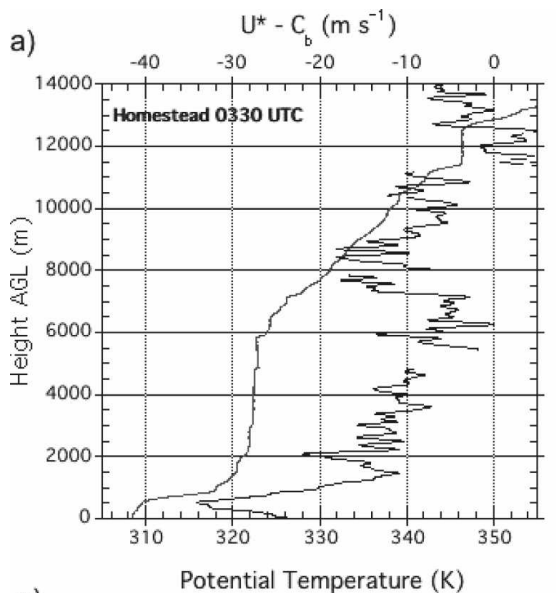

b)

c)
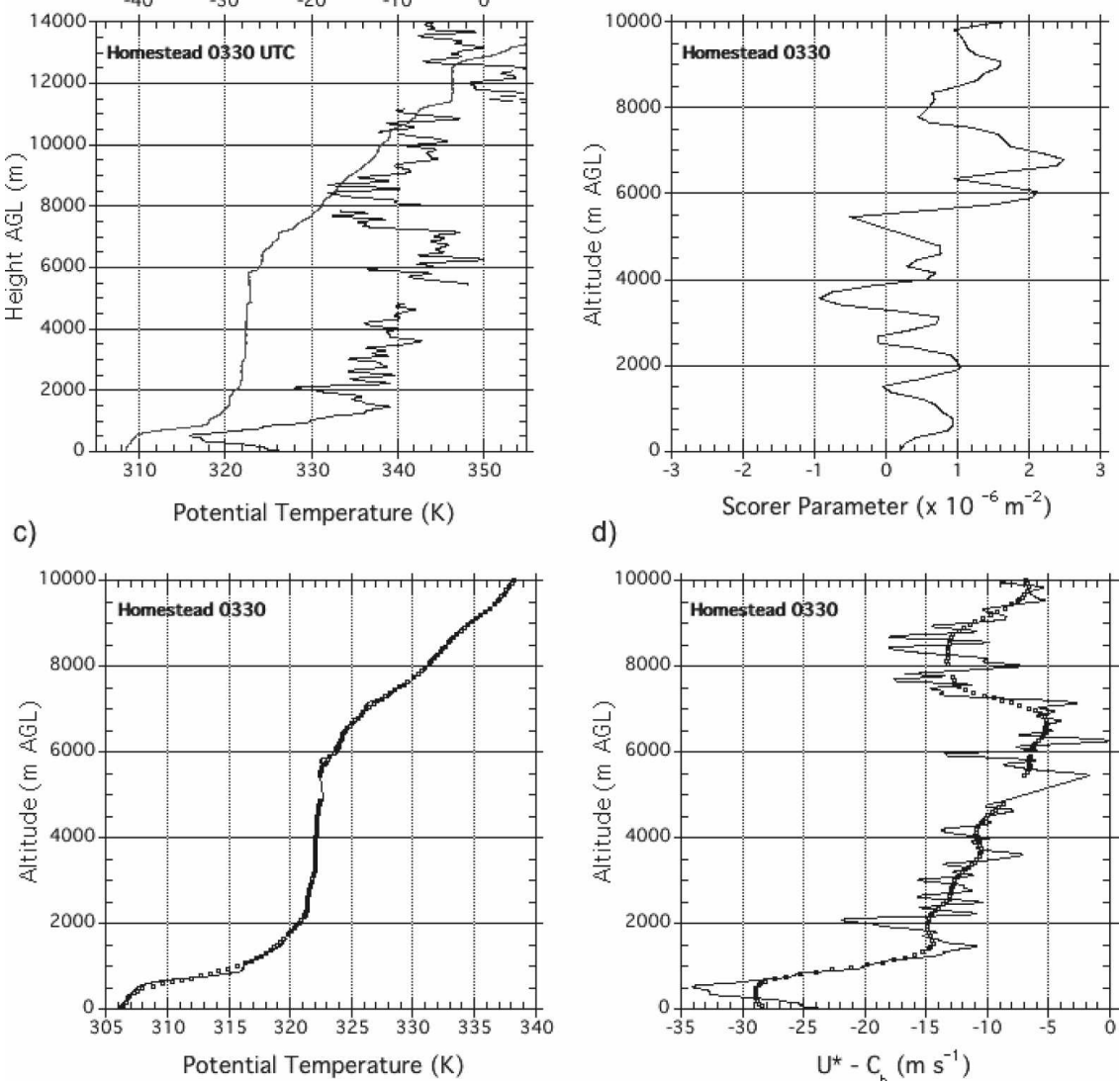

d)

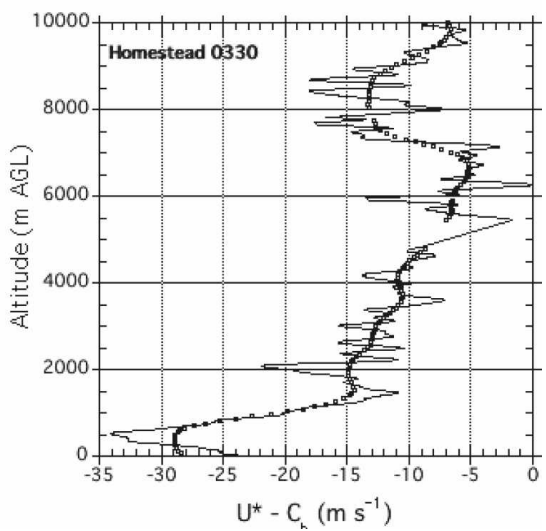

FIG. 13. Diagnostic analyses made on the 0330 UTC Homestead sounding: (a) potential temperature (K, gray line) and bore-relative winds $\left(\mathrm{m} \mathrm{s}^{-1}\right.$, thin black line); (b) Scorer parameter $\left(10^{-6} \mathrm{~m}^{-2}\right)$; (c) smoothed (dots, every 10th data point) and unsmoothed (black line) profiles of potential temperature; and (d) smoothed (dots, every 10th data point) and unsmoothed (black line) profiles of bore-relative winds. Note that wind data are missing at a significant number of vertical levels above $4.2 \mathrm{~km}$ and that (b), (c), and (d) extend only to $10 \mathrm{~km}$.

wave trapping in bore events (Koch et al. 1991; Koch and Clark 1999). The soundings taken at Homestead at 0330 and 0602 UTC both showed a very pronounced low-level southerly jet associated with a strong lowlevel inversion, with the jet being directed perpendicular to the southward-propagating bore.

\section{a. Wave-ducting analyses using NCAR sounding data}

The 1-s $(\sim 4 \mathrm{~m})$ resolution NCAR sounding data made it a challenge to obtain sufficiently smooth wind and potential temperature profiles useful for computing the Scorer parameter-particularly the curvature term-despite the automated QC and low-pass-filtering operations. Potential temperature profiles were subjected to a locally weighted least squares method with a $1 \%-7 \%$ smoothing factor (Chambers et al. 1983), a variant of the standard method that is nearly insensitive to outliers. The winds required an even stronger filtering operation; for this purpose we began by applying a Stineman (1980) function to the data, whose geometric weight output was applied to each data point and to $\pm 10 \%$ of the data range to arrive at an initial smoothed curve. We then further subjected these smoothed data to a light three-point triangular filter to remove remaining "two-delta" waves.

The results of this operation are shown in Fig. 13 for the 0330 UTC sounding and in Fig. 14 for the 0602 UTC sounding. The top left-hand panels depict the full troposphere profiles of unsmoothed potential temperature and bore-relative winds, the top right-hand panels display the Scorer parameter profile, and the bottom leftand right-hand panels show the smoothed (thin black curve) and unsmoothed (dots) profiles of potential tem- 

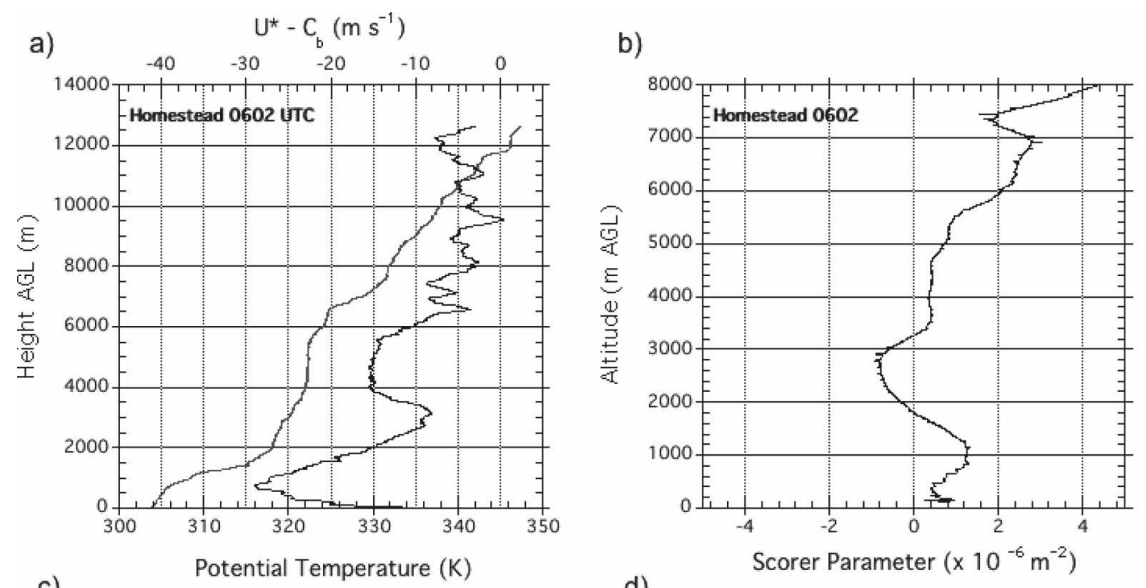

c)

d)
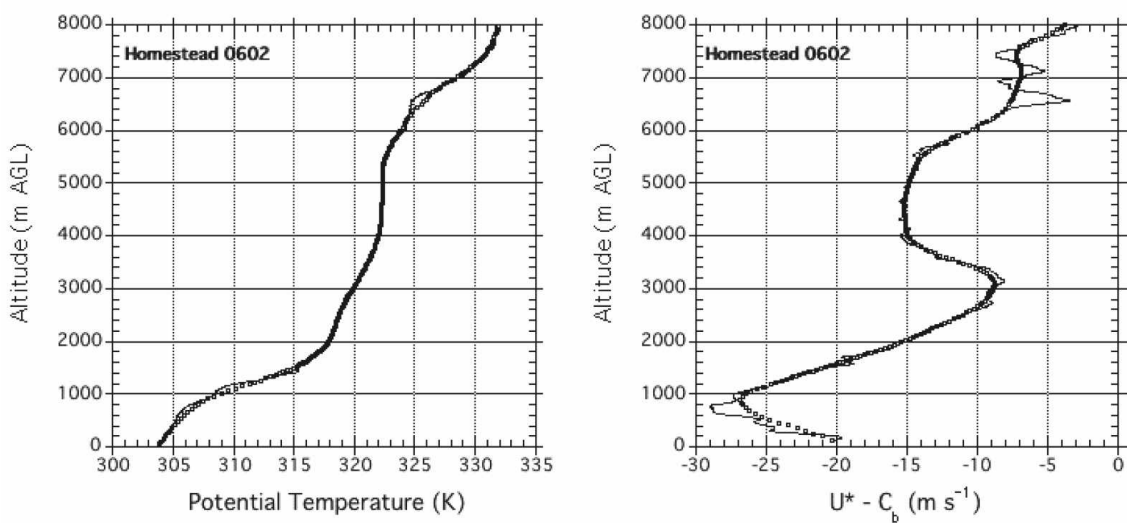

FIG. 14. Same as Fig. 13, but for the 0602 UTC Homestead sounding. Note that (b), (c), and (d) extend only to $8 \mathrm{~km}$.

perature and bore-relative winds, respectively, in the lowest $4000 \mathrm{~m}$. Examining the results for $0330 \mathrm{UTC}$, a very strong low-level jet of $34 \mathrm{~m} \mathrm{~s}^{-1}\left(28 \mathrm{~m} \mathrm{~s}^{-1}\right.$ in an earth-relative framework) was present ahead of the bore at $0.5 \mathrm{~km}$ at the base of a prominent inversion. The Scorer parameter has several layers displaying a decrease with height, but the most pronounced of these features lies above the low-level jet in the less stable layer from 3.1 to $3.6 \mathrm{~km} \mathrm{AGL}$. The net effect of this layer and the two less pronounced ones beneath it would effectively prohibit the vertical propagation of bore wave energy above $3.6 \mathrm{~km}$. This prediction is fairly consistent with the Leandre II and GLOW lidar observations showing a trapped wave mode below $2.7 \mathrm{~km}$, but the noise in the winds and many levels of missing data make this sounding less than ideal.

The results for the more usable 0602 UTC sounding include a pronounced low-level jet of $29 \mathrm{~m} \mathrm{~s}^{-1}$ ahead of the bore and the strong low-level inversion. The Scorer parameter at this time displays a singular negative region, though at a lower altitude of $2.6-2.9 \mathrm{~km}$. Its existence is clearly related to the position of the strong curvature in the wind profile above the jet maximum, and similarly to $3 \mathrm{~h}$ earlier, it provides a mechanism for strong wave trapping.

\section{b. Comparison with hydraulic theory predictions}

Theoretical support for the hypothesis that the convergence boundary displayed the characteristics of an atmospheric bore is provided by comparing the observed depth and speed of propagation of the phenomenon to values predicted from the hydraulic theory for bores. We applied the theory of Rottman and Simpson (1989) for prediction of the bore speed according to (1), but with the correction for a finite fluid. In a manner mirroring the approach used by Koch and Clark (1999; see their Table 3) we also computed other predictions to arrive at a "best" estimate of the theoretical bore speed. The latter theory accounts for the fact that all the energy loss by the bore should occur within the layer overlying the stably stratified waveguide, instead of in the waveguide itself, as normally assumed in hydraulic theory. The average and standard deviation of all four predictions, using input parameter values 
TABLE 1. Input parameter values for prediction of bore propagation speed and depth from hydraulic theory.

\begin{tabular}{lcll}
\hline \hline Symbol & Value (units) & \multicolumn{1}{c}{ Parameter } & \multicolumn{1}{c}{ Data source or method of calculation } \\
\hline$H$ & $12.6 \mathrm{~km}$ & Tropopause height & 0330 UTC Homestead sounding (Fig. 13a) \\
$d_{b}$ & $2.7 \mathrm{~km}$ & Bore depth & Leandre II DIAL (Fig. 6) \\
$h_{0}$ & $0.8 \mathrm{~km}$ & Inversion depth & 0330 UTC Homestead sounding (Fig. 12c) and Leandre II (Fig. 6a) \\
$C_{b}$ & $6.2 \mathrm{~m} \mathrm{~s}^{-1}$ & Bore propagation speed & Isochrone analyses of S-Pol fine lines and pressure jump lines \\
$\Delta \theta$ & $4.0 \mathrm{~K}^{-1}$ & Inversion strength & 0330 UTC Homestead sounding (Fig. 13c) \\
$U$ & $22.0 \mathrm{~m} \mathrm{~s}^{-1}$ & Mean head wind & 0330 UTC Homestead sounding (Fig. 13a) using 6.2 m s ${ }^{-1}$ bore speed \\
$\theta_{\mathrm{vw}}-\theta_{\mathrm{vc}}$ & $11.0 \mathrm{~K}$ & Cooling with density current & Temperature drop at source of pressure jump (station SW7, Fig. 7a) \\
$C_{\mathrm{dc}}$ & $15.7 \mathrm{~m} \mathrm{~s}^{-1}$ & Density current speed & Isochrones radar fine line and pressure jumps prior to 0200 UTC \\
$\Delta p$ & $6.5 \mathrm{hPa}$ & Pressure jump & Observed 60-min change at station KULS (Fig. 1) \\
\hline
\end{tabular}

shown in Table 1, are shown in Table 2. According to (2), the prediction for bore strength or depth $\left(d_{b}\right)$ is based on two parameter estimates (see Fig. 16 in Koch et al. 1991): (i) the ratio of the density current speed to the gravity-wave speed for the given inversion depth and strength $\left(C_{\mathrm{dc}} / C_{\mathrm{gw}}\right)$ and (ii) the density current depth $\left(d_{\mathrm{dc}}\right)$ normalized by the inversion depth $\left(h_{0}\right)$, where

$$
\begin{aligned}
d_{\mathrm{dc}} & =\frac{\theta_{\mathrm{vc}} \Delta p}{\rho_{w} g\left[\left(p_{c} / p_{w}\right) \theta_{\mathrm{vw}}-\theta_{\mathrm{vc}}\right]} \cong\left(\frac{C_{\mathrm{dc}}}{\mathrm{Fr}}\right)^{2}\left(\frac{\theta_{v}}{g \Delta \theta_{v}}\right), \\
C_{\mathrm{dc}} & =\operatorname{Fr}\left(\frac{\Delta p}{\rho_{w}}\right)^{1 / 2} \approx \operatorname{Fr}\left(g d_{\mathrm{dc}} \frac{\Delta \theta_{v}}{\theta_{v}}\right)^{1 / 2}, \quad \text { and } \\
C_{\mathrm{gw}} & =\sqrt{g \Delta \theta_{v}\left(h_{0} / \theta_{v}\right)}
\end{aligned}
$$

are expressions for the density current depth, density current speed, and gravity-wave speed for the given inversion properties (Koch et al. 1991), $\theta_{\mathrm{vw}}$ and $\theta_{\mathrm{vc}}$ are the virtual potential temperatures in the warm and cold air masses, respectively, $\Delta \theta_{v}$ is the temperature jump across the inversion layer, $\mathrm{Fr}$ is a representative Froude number (assumed to be 0.95), and $\Delta p$ represents the hydrostatic portion of the pressure jump at the head of the density current. The values for these and other quantities and the sources for these estimates are shown in Table 1. The conclusions drawn from these computations are that the bore depth observed by Leandre II $(2.7 \mathrm{~km})$ is quite close to the predicted value $(2.2 \mathrm{~km})$ and that the observed bore speed of motion $\left(6.2 \mathrm{~m} \mathrm{~s}^{-1}\right)$ falls within the standard deviation of the various theoretical estimates $\left(6.4 \pm 1.2 \mathrm{~m} \mathrm{~s}^{-1}\right)$. Thus, these comparisons made with theory provide strong support for our contention that the observed phenomenon was a bore.

\section{Conclusions}

The structure and dynamics of a bore that was generated during the early evening hours of 20 June 2002 and its evolution into a stunning amplitude-ordered train of solitary waves have been derived from synthesis of the airborne Leandre II differential absorption lidar (DIAL), S-band dual-polarization Doppler radar (SPol), and the Goddard Lidar Observatory for Winds (GLOW) Doppler lidar. Also used in this study were highly detailed surface mesonetwork and NCAR Integrated Sounding System (ISS) data. The nadir-pointing DIAL system was flown at an altitude of $4.5 \mathrm{~km}$ perpendicular to the bore and wave fronts. GLOW mea-

\begin{tabular}{|c|c|c|c|}
\hline Symbol & Value (units) & Parameter & Data source or method of calculation \\
\hline$d_{b} / h_{0}$ & 3.4 & Observed bore strength & Ratio of observed bore depth to inversion depth \\
\hline$d_{\mathrm{dc}}$ & $1.4 \mathrm{~km}$ & Density current depth & Density current depth according to $(8 \mathrm{a})$ \\
\hline$d_{\mathrm{dc}} / h_{0}$ & 1.78 & Normalized density current depth & Ratio of density current depth to inversion depth \\
\hline & $11.4 \pm 0.2 \mathrm{~m} \mathrm{~s}^{-1}$ & Density current speed & Ground-relative density current speed according to (8b) \\
\hline$C_{\mathrm{gw}}$ & $10 \mathrm{~m} \mathrm{~s}^{-1}$ & Gravity-wave speed & Gravity-wave speed according to $(8 \mathrm{c})$ \\
\hline$C_{\mathrm{dc}} / C_{\mathrm{gw}}$ & 1.57 & Froude number & Ratio of values for density current and gravity-wave speeds \\
\hline$d_{b} / h_{0}$ & 2.7 & Predicted bore strength & Hydraulic theory of Rottman and Simpson (1989) \\
\hline$d_{b}$ & $2.2 \mathrm{~km}$ & Predicted bore depth & Predicted bore strength and observed inversion depth \\
\hline$C_{b}$ & $6.4 \pm 1.2 \mathrm{~m} \mathrm{~s}^{-1}$ & Predicted bore propagation speed & $\begin{array}{l}\text { Mean and standard deviation of bore propagation speed } \\
\text { predicted from theory using predicted bore depth and observed } \\
\text { inversion depth }\end{array}$ \\
\hline
\end{tabular}
surements were made with resolutions of $45 \mathrm{~m}$ in range

TABLE 2. Predicted bore propagation speed and depth from hydraulic theory using observed input parameter values in Table 1. 
(averaged to $150 \mathrm{~m}$ ) and $3.5 \mathrm{~min}$ in time, and displayed high signal-to-noise returns in the lowest $2.2 \mathrm{~km}$ of the atmosphere. The NCAR S-Pol provided radar reflectivity and radial velocity fields at 5-min intervals in both the plan position indicator (PPI) and range-height indicator (RHI) modes.

The bore and subsequent soliton were generated as a density current associated with cold outflow from a mesoscale convective system encountered a stable nocturnal boundary layer and a very strong low-level jet in southwestern Kansas. S-Pol reflectivity and radial velocity and DIAL mixing ratio vertical cross sections showed five to seven solitary waves, with an average horizontal wavelength of $10.5 \mathrm{~km}$, lacking any discernible vertical tilt or propagation relative to the motion of the bore. This attribute suggests trapped waves in the lee of the bore head in the lowest $2.7 \mathrm{~km}$ of the atmosphere. DIAL also revealed that the bore lifted the inversion originally located at $0.8 \mathrm{~km}$ AGL to an altitude of $1.4 \mathrm{~km}$ and demonstrated an increased flattening of the leading wave in the wave train with time, a change that may have brought about the demise of the soliton.

The GLOW Doppler lidar provided detailed measurements allowing for the determination of the twodimensional vertical circulation accompanying the dissipating soliton. Upon rotating the time-height $(t, z)$ winds into the bore reference frame and applying a time-to-space transformation, the bore-relative winds could be determined on a uniform $(x, z)$ grid. This made it possible to compute the vertical velocities by upward integration of the mass continuity equation, from which the two-dimensional vertical circulation system was obtained. The veracity of the results was corroborated by (i) the resolved updrafts and downdrafts being very similar in number to the oscillations seen in the S-Pol and DIAL displays, (ii) the first significant updraft being found precisely at the time that the bore passed over the GLOW facility (in good agreement with the value seen in MAPR data), and (iii) the correlation between the sudden ramping upward in the depth of high GLOW photon-count values and the time of the first significant updraft. GLOW resolved a 5.8$\mathrm{km}$ subharmonic wavelength disturbance not detected by the other two remote sensing systems. However, there was an indication of a similar feature in the DIAL data at longer distances behind the bore head where the larger-amplitude, $10.5-\mathrm{km}$ features did not mask the presence of the smaller waves. Additional evidence in support of the validity of the GLOW results rested in the fact that layer displacements computed using the derived GLOW vertical motions agreed very well with those implied by the changes in height of the Leandre II mixing ratio surfaces.

Analysis of the sounding data showed that because of a rapid decrease in the Scorer parameter (due to a highly pronounced curvature in the profile of the borerelative winds), upward leakage of solitary wave energy was trapped in the lowest $\sim 2.5 \mathrm{~km}$. This result explained the structures seen in the DIAL and S-Pol displays. Finally, the depth and speed of propagation of the bore seen in the DIAL and mesoanalyses were shown to be consistent with the predictions from hydraulic theory for bores. In summary, this synthesis of data from the various remote sensing systems (including use of specialized analysis techniques allowing for cross validation and comparisons with theory) permitted detailed investigation of the structure and dynamics of complex atmospheric phenomena in a consistent manner. The technique developed herein for analysis of ground-based Doppler lidar data should be extended to the study of other essentially two-dimensional atmospheric phenomena, including sharp cold fronts, gravity waves, sea breezes, and thunderstorm outflow boundaries.

Acknowledgments. We thank Didier Bruneau and Pascal Genau (Service d'Aéronomie) as well as Frédéric Blouzon, Patricia Delville, Abdel Abchiche, and Nadir Amarouche (Division Technique of Institut National des Sciences de l'Univers) for operating LEANDRE II onboard the NRL P-3. Huailin Chen and Joe Comer operated GLOW during IHOP_2002 and processed the lidar winds. The University Corporation for Atmospheric Research/Joint Office for Science Support (UCAR/JOSS) created the highly useful composites of 1-, 5-, and 60-min surface mesonet datasets. Rita Roberts of NCAR provided assistance in creating the surface and radar composite analyses. The efforts of Tammy Weckwerth of NCAR to activate an RHI sequence for the S-Pol scanning just before the bore struck Homestead made it possible to see some important aspects of the solitary waves. Comments made by the reviewers appreciably benefited this paper.

\section{REFERENCES}

Bösenberg, J., 1998: Ground-based differential absorption lidar for water-vapor and temperature profiling: Methodology. Appl. Opt., 37, 3845-3860.

Bruneau, D., P. Quaglia, C. Flamant, J. Pelon, and M. Meissonnier, 2001a: Airborne lidar LEANDRE II for water-vapor profiling in the troposphere. I. System description. Appl. Opt., 40, 3450-3461.

,,,--- and,$- 2001 \mathrm{~b}$ : Airborne lidar LEANDRE II 
for water-vapor profiling in the troposphere. II. First results. Appl. Opt., 40, 3462-3475.

Chambers, J. M., W. S. Cleveland, B. Kleiner, and P. A. Tukey, 1983: Graphical Methods for Data Analysis. Duxbury Press, $395 \mathrm{pp}$.

Christie, D. R., 1989: Long nonlinear waves in the lower atmosphere. J. Atmos. Sci., 46, 1462-1491.

_ , K. J. Muirhead, and A. L. Hales, 1979: Intrusive density flows in the lower troposphere: A source of atmospheric solitons. J. Geophys. Res., 84, 4959-4970.

Cohn, S. A., W. O. J. Brown, C. L. Martin, M. E. Susedik, G. Maclean, and D. B. Parsons, 2001: Clear air boundary layer spaced antenna wind measurement with the Multiple Antenna Profiler (MAPR). Ann. Geophys., 19, 845-854.

Crook, N. A., 1988: Trapping of low-level internal gravity waves. J. Atmos. Sci., 45, 1533-1541.

Doviak, R. J., and R. Ge, 1984: An atmospheric solitary gust observed with a Doppler radar, a tall tower, and a surface network. J. Atmos. Sci., 41, 2559-2573.

Droegemeier, K. K., and R. B. Wilhelmson, 1985: Threedimensional numerical modeling of convection produced by interacting thunderstorm outflows. Part I: Control simulation and low-level moisture variations. J. Atmos. Sci., 42, 23812403.

Gentry, B. M., and H. Chen, 2002: Performance validation and error analysis for a direct-detection molecular Doppler lidar. Lidar Remote Sensing for Industry and Environment Monitoring III, U. N. Singh, T. Itabe, and Z. Liu, Eds., International Society for Optical Engineering (SPIE Proceedings, Vol. 4893), 287-294.

,$- \ldots$, and S. X. Li, 2000: Wind measurements with a 355-nm molecular Doppler lidar. Opt. Lett., 25, 1231-1233.

Haase, S. P., and R. K. Smith, 1989a: The numerical simulation of atmospheric gravity currents. Part I: Neutrally stable environments. Geophys. Astrophys. Fluid Dyn., 46, 1-33.

- , and $-1989 \mathrm{~b}$ : The numerical simulation of atmospheric gravity currents. Part II: Environments with stable layers. Geophys. Astrophys. Fluid Dyn., 46, 35-51.

Jin, Y., S. E. Koch, Y.-L. Lin, F. M. Ralph, and C. Chen, 1996: Numerical simulations of an observed gravity current and gravity waves in an environment characterized by complex stratification and shear. J. Atmos. Sci., 53, 3570-3588.

Karyampudi, V. M., S. E. Koch, C. Chen, J. W. Rottman, and M. L. Kaplan, 1995: The influence of the Rocky Mountains on the 13-14 April 1986 severe weather outbreak. Part II: Evolution of a prefrontal bore and its role in triggering a squall line. Mon. Wea. Rev., 123, 1423-1446.
Klemp, J. B., R. Rotunno, and W. C. Skamarock, 1997: On the propagation of internal bores. J. Fluid Mech., 331, 81-106.

Knupp, K., 2006: Observational analysis of a gust front to bore to solitary wave transition within an evolving nocturnal boundary layer. J. Atmos. Sci., 63, 2016-2035.

Koch, S. E., and W. Clark, 1999: A nonclassical cold front observed during COPS-91: Frontal structure and the process of severe storm initiation. J. Atmos. Sci., 56, 2862-2890.

- , P. B. Dorian, R. Ferrare, S. H. Melfi, W. C. Skillman, and D. Whiteman, 1991: Structure of an internal bore and dissipating gravity current as revealed by Raman lidar. Mon. Wea. Rev., 119, 857-887.

- F. Einaudi, P. B. Dorian, S. Lang, and G. H. Heymsfield, 1993: A mesoscale gravity wave event observed during CCOPE. Part IV: Stability analysis and Doppler-derived wave vertical structure. Mon. Wea. Rev., 121, 2483-2510.

—, W. Feltz, F. Fabry, M. Pagowski, B. Geerts, K. M. Bedka, D. O. Miller, and J. W. Wilson, 2008: Turbulent mixing processes in atmospheric bores and solitary waves deduced from profiling systems and numerical simulation. Mon. Wea. Rev., 136, 1373-1400.

Lutz, J., P. Johnson, B. Lewis, E. Loew, M. Randall, and J. VanAndel, 1995: NCAR's S-Pol: Portable polarimetric Sband radar. Preprints, Ninth Symp. on Meteorological Observations and Instrumentation, Charlotte, NC, Amer. Meteor. Soc., 408-410.

Maxworthy, T., 1980: On the formation of nonlinear internal waves from the gravitational collapse of mixed regions in two and three dimensions. J. Fluid Mech., 96, 47-64.

Mueller, C. K., and R. E. Carbone, 1987: Dynamics of a thunderstorm outflow. J. Atmos. Sci., 44, 1879-1898.

Rottman, J. W., and J. E. Simpson, 1989: The formation of internal bores in the atmosphere: A laboratory model. Quart. J. Roy. Meteor. Soc., 115, 941-963.

Simpson, J. E., 1987: Gravity Currents: In the Environment and the Laboratory. Halsted, 244 pp.

Stineman, R. W., 1980: A consistently well-behaved method of interpolation. Creat. Comput., 6, 54-57.

Trexler, C. M., and S. E. Koch, 2000: The life cycle of a mesoscale gravity wave as observed by a network of Doppler wind profilers. Mon. Wea. Rev., 128, 2423-2446.

Weckwerth, T. M., and Coauthors, 2004: An overview of the International $\mathrm{H}_{2} 0$ Project (IHOP_2002) and some preliminary highlights. Bull. Amer. Meteor. Soc., 85, 253-277.

Wilson, J. W., and W. E. Schreiber, 1986: Initiation of convective storms at radar-observed boundary-layer convergence lines. Mon. Wea. Rev., 114, 2516-2536. 